\title{
Application of model based post-stack inversion in the characterization of reservoir sands containing porous, tight and mixed facies: A case study from the Central Indus Basin, Pakistan
}

\author{
Muhammad Togeer $^{1}$, Aamir Ali ${ }^{1, *}{ }^{\infty}$, Tiago M Alves ${ }^{2}$, Ashar Khan $^{1}$, \\ Zubair $^{3}$ and Matloob Hussain ${ }^{1}$ \\ ${ }^{1}$ Department of Earth Sciences, Quaid-i-Azam University, Islamabad 45320, Pakistan. \\ 2 3D Seismic Lab, School of Earth and Ocean Sciences, Cardiff University, Cardiff CF10 3AT, UK. \\ ${ }^{3}$ Software Integrated Solutions, Schlumberger, Pakistan. \\ *Corresponding author.e-mail: aamirali.geo@gmail.com aakgeo82@qau.edu.pk
}

MS received 7 May 2020; revised 1 November 2020; accepted 10 November 2020

Porosity is a key parameter for reservoir evaluation. Inferring the porosity from seismic data is often challenging and prone to uncertainties due to number of factors. The main aim of this paper is to show the applicability of seismic inversion on old vintage seismic data to map spatial porosity at reservoir level. 3D-seismic and wireline log data are used to map the reservoir properties of the Lower Goru productive sands in the Gambat Latif block, Central Indus Basin, Pakistan. The Lower Goru formation was interpreted with the help of seismic and well data. Interpreted horizons are thus further used in model-based seismic inversion techniques to map the spatial distribution of porosity. Well-log data are used in the construction of low acoustic impedance models. Calibration of reservoir porosity with inverted acoustic impedance is achieved through well-log data. The results from model-based inversion reasonably estimate the porosity distribution within the C-sand interval of the Lower Goru Member. After post-stack inversion, the porosity values at wells Tajjal-01, Tajjal-02 and Tajjal-03 are 10\%, 8\% and 12\%, respectively. Porosity values calculated from post-stack inversion at the corresponding well locations are in good agreement with the borehole-derived porosity.

Keywords. Indus basin; post-stack inversion; model-based inversion; reservoir modelling.

\section{Introduction}

Reservoir characterization comprises the estimation of key reservoir properties such as porosity, permeability, upper and lower reservoir boundaries, their lateral and vertical extent, heterogeneity, and type and volume of subsurface fluids (Avseth et al. 2005; Bacon et al. 2007). Seismic and well-log data are typically used to estimate reservoir properties at different scale(s) of investigation Published online: 30 March 2021
(Chen and Sidney 1997; Lindseth 1979; King 1990; Hearts et al. 2002; Chopra and Marfurt 2007). Interpolations and other geostatistical techniques also help to efficiently link seismic, well-log, core data to field observations, improving our understanding of the local geology (Caers et al. 2001; Mukerji et al. 2001; Walls et al. 2004; Bosch et al. 2010; Azevedo et al. 2017).

Seismic inversion techniques are used to retrieve acoustic impedance from seismic reflection profiles 
and 3D volumes, spatial distribution of depositional facies, local petrophysical properties and distinct reservoir parameters (Angeleri and Carpi 1982; Yao and Gan 2000; Walls et al. 2004; Bosch et al. 2009; Grana and Dvorkin 2011). Seismic, well-log and inversion data are later combined to derive the different physical parameters (i.e., porosity and lithological information) of key reservoir intervals (Landa et al. 2000; Yao and Gan 2000; Leite and Vidal 2011; Simm and Bacon 2014).

The benefits of seismic inversion include an improved seismic resolution (Delaplanche et al. 1982), and better seismic interpretation owing to the fact that layer-oriented impedance displays more complete constraints for reservoir models (Ashcroft 2011). For post-stack data, the main inversion techniques are sparse-spike, model-based and coloured inversion, which are based on different algorithms (Silva et al. 2004; Veeken and Silva 2004; Veeken and Rauch-Davies 2006; Veeken 2007; Ashcroft 2011; Wang 2017).

Post-stack seismic inversion methods utilize post-stack seismic data. Appropriate processing parameters are required for amplitude and phase preservation with higher signal-to-noise ratios (Simm and Bacon 2014). Filtered lower frequencies in the processed data should be compensated by incorporating low frequency models for inversion (Sams and Carter 2017). Likewise, the absence of higher frequencies due to absorption should also be considered (Vecken and Da Silva 2004). Due to the band-limited nature of post-stack seismic data, the absence of higher and lower frequencies may result in ambiguities when resolving thin beds and estimating local elastic properties (Zhang et al. 2012; Rosa 2018). Nevertheless, despite the inherent limitations of post-stack inversion techniques, their applicability and popularity are growing for a range of geophysical and geological studies $(\mathrm{Li}$ 2014; Verma et al. 2018; Gogoi and Chatterjee 2019; Singha et al. 2019; Teixeira and Maul 2020).

Seismic inversion techniques are often applied in the different basins worldwide to find the acoustic impedance and reservoir parameters (Alavi 2004; Leite and Vidal 2011). In several Asian basins seismic inversion techniques have been successfully applied to characterize hydrocarbon bearing strata (Karbalaali et al. 2013; Sinha and Mohanty 2015; Kumar et al. 2016; Das et al. 2017; Iravani et al. 2017; Jafari et al. 2017).

Owing to its hydrocarbon potential, the Indus basin has been extensively studied since the 1930's (de Terra et al. 1936; Williams 1959; Quadri 1986; Zaigham and Mallick 2000). The presence of the Lower Goru Formation, a proven reservoir, has been demonstrated in the region. However, important variations in the thickness and reservoir properties of the Lower Goru Formation are also reported within the Indus Basin (Khattak et al. 1999).

The aim of this paper is to map the spatial porosity of a reservoir interval using a limited dataset. Old vintage 3D-seismic data are used to accomplish this task. Certain uncertainties associated with porosity estimation include the inherent limitation of seismic techniques, i.e., seismic resolution, applied seismic data processing algorithms, limitations of seismic inversion techniques themselves, and the seismic character of the local geology. The only control points are the sparse well data used to validate the inversion process. The results thus obtained are subjective to discussion and criticism, but the inversion process we present leads to the best results when compared to all the available techniques.

Seismic data was used to map key seismicstratigraphic horizons, and to delineate structural and stratigraphic features of relevance in the study area, the Gambat-Latif block of the Central Indus Basin (figure 1). Seismic and well-log information from three distinct wells, Tajjal-01, Tajjal-02 and Tajjal-03 (figure 2) were used to complete our inversion method. Well-log data comprised gamma ray, resistivity, caliper, density, and sonic logs. Well-log data were used to tie seismic to well information, and to document the spatial variability of the main reservoir interval (Lower Goru Sand). A geo-statistical relationship was also established, at the three well locations, between acoustic impedance and porosity. Model-based post-stack impedance and geo-statistical relationships are thus used in this work as 'external' attributes to estimate reservoir porosity.

\section{Geological setting}

Geologically, the Gambat-Latif block is part of the Central Indus Basin of Pakistan, as shown in the tectonic map in figure 1 . It is located in the Khairpur district of Sindh, Pakistan. The spatial coverage of the $3 \mathrm{D}$ seismic data interpreted in this paper, and the relative location of wells Tajjal-01, Tajjal-02 and Tajjal-03, are shown in figure 2. The study area comprises a series of horst and graben 


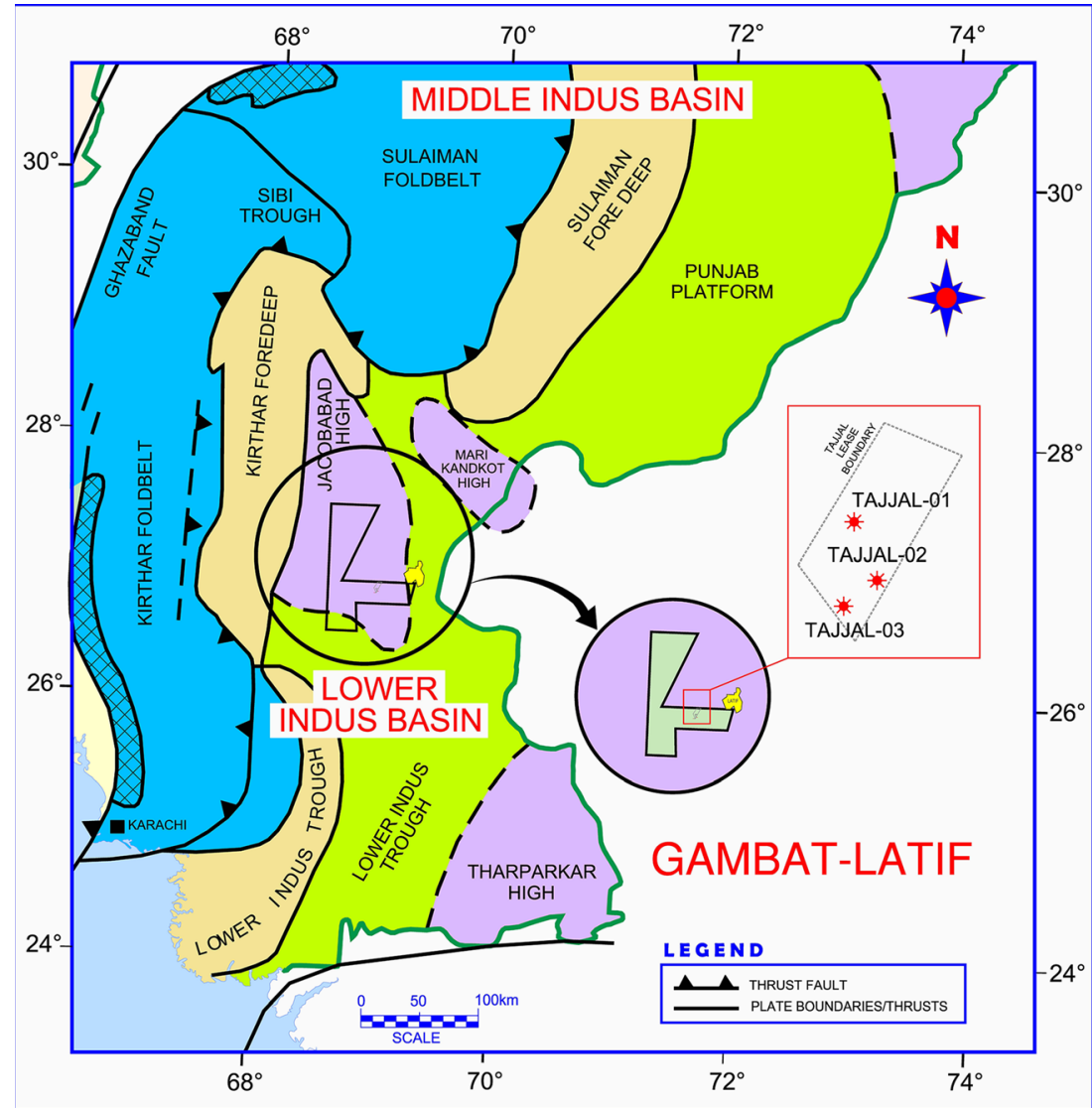

Figure 1. Generalized tectonic map of the study area (modified from Kazmi and Rana 1982). The study area, the Gambat-Latif block with marked well locations (Tajjal-01, Tajjal-02 and Tajjal-03), is part of the Central Indus Basin, Pakistan.

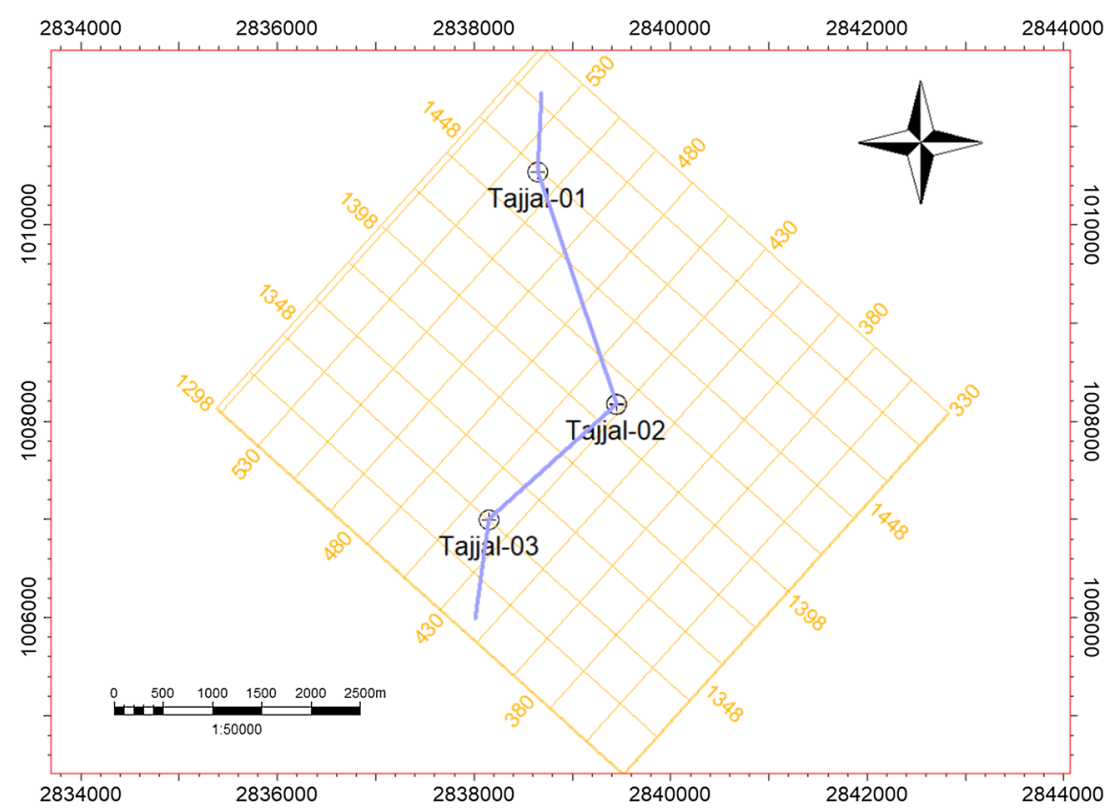

Figure 2. Spatial coverage of seismic and well-log data used in this study. The coordinate system used is the Universal Transverse Mercator $42 \mathrm{~N}$.

structures at Paleocene level, extending into Cretaceous strata. The main reservoirs intervals of the Central and Lower Indus Basin are part of the Lower Goru Formation of Cretaceous age (figure 3). The Lower Goru Formation is further subdivided into 'A', 'B', 'C' and 'D' intervals. 


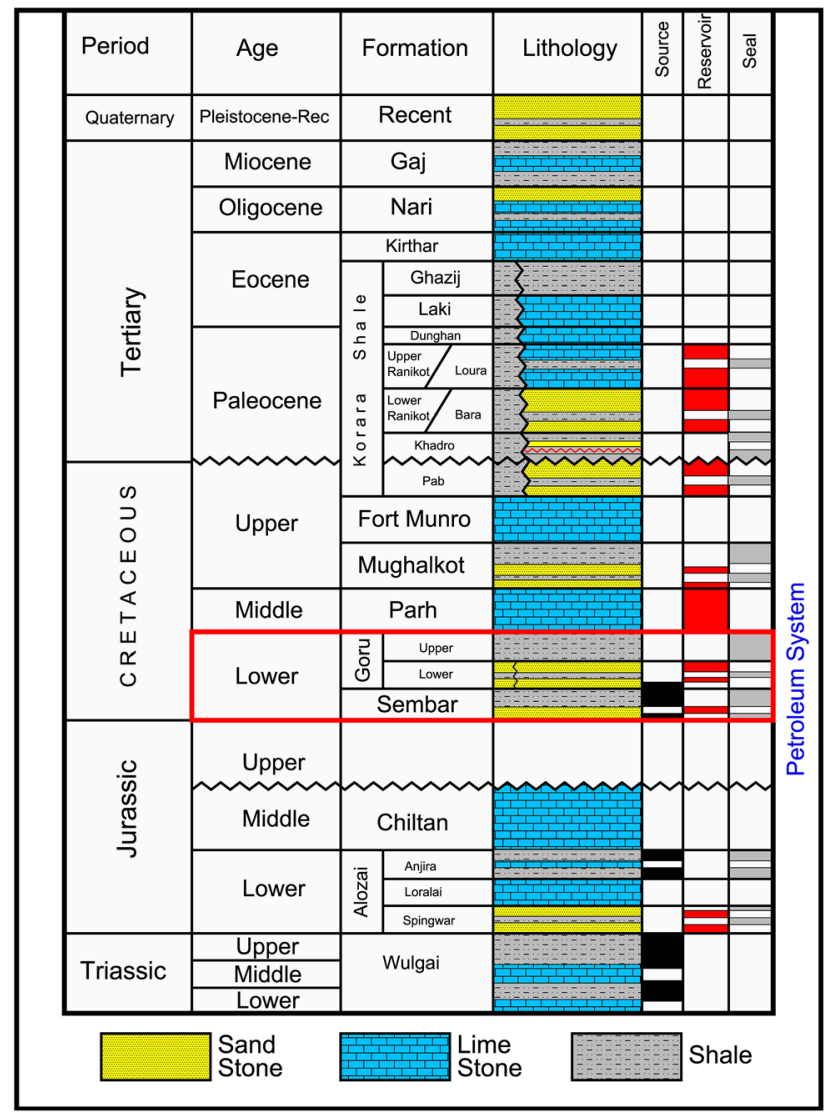

Figure 3. Simplified stratigraphic chart for the Lower Indus Basin. The studied reservoir interval (C-sand) is part of the Lower Goru Formation, which is Early Cretaceous in age. Stratigraphic chart is modified from Abbasi et al. (2016).

These sandy intervals are proven reservoirs (Ahmed et al. 2004), and are limited to the east and west by regional NW-trending extensional faults (Kazmi and Abbasi 2008).

A regional stratigraphic chart for the Central and Lower Indus Basins is displayed in figure 3. The Cretaceous stratigraphic succession comprises the Sembar, Goru, Parh, MoghalKot, Fort Munro and Pab Formations (Afzal et al. 2009; Abbasi et al. 2016). The Sembar Formation is a proven source rock throughout the Indus Basin (Robison et al. 1999; Wandrey et al. 2004; Aziz et al. 2018). In addition, the Intra Lower Goru shales of Cretaceous age have shown secondary, but important, source potential (Wandrey et al. 2004).

Depositional environments, diagenetic changes, shale intercalations and shale distribution styles are key factors generating reservoir heterogeneity within the Lower Goru Formation (Berger et al. 2009; Ali et al. 2016). Hence, reservoir properties in the Lower Goru Formation have been estimated in the published literature using a multitude of techniques, from detailed structural/stratigraphic interpretation (Akhter et al. 2015), to rock physics modelling (Azeem et al. 2017; Toqeer and Ali 2017), AVA analyses (Ali et al. 2016; Anwer et al. 2017) and seismic inversions (Ali et al. 2018).

\section{Methodology}

For this study only 3D seismic and well-log data are available. 3D seismic data was acquired during 2005 by BGP International via a Vibroseis source for data acquisition. The processed 3D data set has a bin spacing of $25 \times 25 \mathrm{~m}$, with sampling at $2 \mathrm{~ms}$ and a dominant frequency of $35 \mathrm{~Hz}$ at reservoir level. The processed 3D seismic data are timemigrated and zero-phased. The acquisition and processing parameters are outlined in the table 1 .

Well-log data from three wells are used in this work. These wells were drilled to variable total depths in the years 2007-2008. The total drilled depth of Tajjal-01 is $4506 \mathrm{~m}$, Tajjal-02 is $3836 \mathrm{~m}$ and Tajjal-03 well is $3800 \mathrm{~m}$, respectively. Only Tajjal-01 well is producing gas at present, while Tajjal-02 and Tajjal-03 are reported suspended and abandoned. Prior to well-log data analysis the quality of data was checked based on the analysis of their calliper logs. The necessary corrections were made prior the successive calculations. The methodology can be divided into three parts. A comprehensive summary of main steps involved in this study is given as follows.

\subsection{Seismic interpretation}

Seismic interpretation is the starting point in reservoir characterization (Simm and Bacon 2014). It is paramount to tie well to seismic information to correctly interpret any relevant stratigraphic horizons. A well tie not only correlates the geology with seismic data but also assists zero-phase checking, horizon identification and wavelet extraction, amongst other parameters (White 2003; Bacon et al. 2007; Simm and Bacon 2014; Liner 2016). For these reasons, synthetic seismograms were produced in this work by convolving reflectivity from the digitised acoustic and density logs from well Tajjal-01 with the extracted seismic wavelet. The resulting synthetic seismogram is correlated with seismic inline 1459 at the exact location of the Tajjal-01 well (figure 4). In addition, horizon picking, and fault interpretation helped to characterize the spatial distribution of horizons and structural features in the study area (figure 5). In this work, the 3D seismic 
Table 1. Key recording and processing parameters of the 3D seismic dataset used in this study.

Key 3D seismic data acquisition parameters

\begin{tabular}{llll}
\hline Source & & Recording parameters \\
Vibroseis & 4 & Sampling interval & Record length \\
No. of sweeps & 4 & Geometry & $2 \mathrm{~ms}$ \\
Sweep frequency sweep length & $8-80 \mathrm{~Hz}$ & Receiver line interval & $300 \mathrm{~m}$ \\
Sweep type & $16 \mathrm{~s}$ & Source line onterval \\
Sweep taper & Linear & \\
Receiver parameters & & \\
Number of geophones & $2 \times 12$ & \\
Geophone array & Rectangular & \\
\hline
\end{tabular}

Processing parameters

Vibroseis minimum phase conversion

Amplitude adjustment

Static correction

3D FK coning filter in cross

spread domain

Amplitude vs. offset corrections

3D surface consistent amplitude corrections
$\mathrm{Q}$ phase and amplitude compensation 3D surface consistent spiking deconvolution Spectral flattening $(6-80 \mathrm{~Hz})$

Velocity analysis

3D surface consistent residual static computation and application

Offset regularization DMO
3D prestack migration velocity analysis

$3 \mathrm{D}$ full isotropic prestack time migration Foot print noise attenuation

3D FXY Random noise attenuation

Filter equivalent spectral balancing to preserve amplitude

Time variant filter interpretation was performed and used as a geological model for seismic inversion.

\subsection{Petrophysical analysis and interpretation}

Petrophysical analyses for the C-sand interval of the Lower Goru Member were carried out in this work to determine the relevant reservoir parameters. Different reservoir parameters such as volume of shale $\left(V_{s h}\right)$, effective porosity $\left(\varphi_{e}\right)$, water saturation $\left(S_{w}\right)$, etc., were estimated by using empirical relationships from well-log data. Effective porosity $\varphi_{e}$ is calculated using the following mathematical equation (Tiab and Donaldson 2015)

$$
\varphi_{e}=\varphi_{t o t}\left(1-V_{s h}\right),
$$

where $\varphi_{\text {tot }}$ denotes the total porosity calculated form sonic, density and neutron porosity logs, respectively. $V_{s h}$ is calculated using the gamma ray log. Similarly, $S_{w}$ is calculated using Archie's equation as given below (Tiab and Donaldson 2015)

$$
S_{w}=\sqrt[n]{\frac{F R_{w}}{R_{t}}}
$$

In equation (2), $R_{w}$ and $R_{t}$ denote the resistivity of water and true resistivity of the formation calculated from resistivity logs. $F$ is referred to as formation factor as calculated from the following equation (Tiab and Donaldson 2015)

$$
F=\frac{a}{\varphi^{m}},
$$

where $a$ is a constant and $m$ is cementation factor, respectively. The values of $a$ and $m$ are taken to be respectively equal to 1 and 2 for sandstones. Once $S_{w}$ is calculated, hydrocarbon saturation $\left(S_{h}\right)$ can be calculated as (Tiab and Donaldson 2015)

$$
S_{h}=1-S_{w} .
$$

Table 2 outlines the distinct reservoir parameters calculated with the help of petrophysical analyses.

\subsection{Seismic inversion}

Seismic inversion is the process of transforming seismic interface properties into layer properties. Hence, seismic inversion greatly helps the interpretation and quantification of reservoir properties and their spatial distribution (Yilmaz 2001; Ashcroft 2011). The generalised workflow for seismic inversion applied in this study is based on Ali et al. (2018). Caveats associated with our approach are briefly discussed in Lindseth (1979), and Oldenburg et al. $(1983,1986)$.

For this study we applied a model-based inversion (Russell and Dommico 1988), which is a type of deterministic inversion. Model-based inversion is 


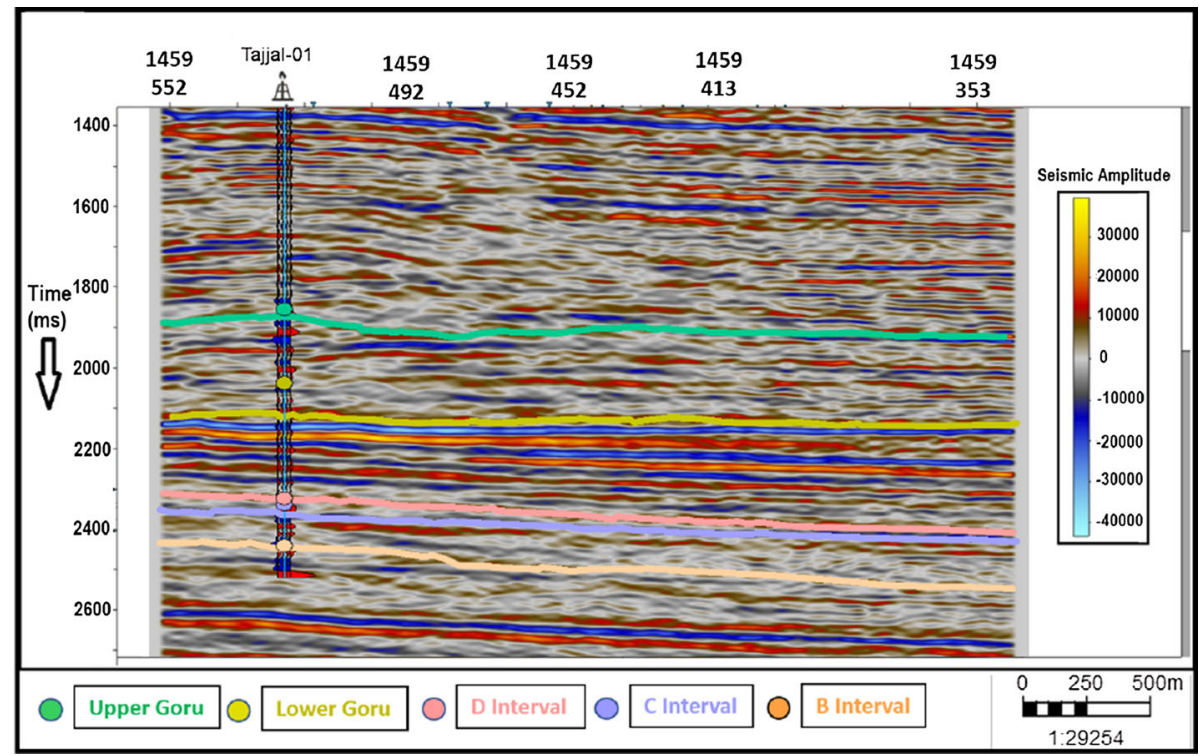

Figure 4. Synthetic seismogram at the location of the Tajjl-01 well, superimposed on seismic inline 1459.

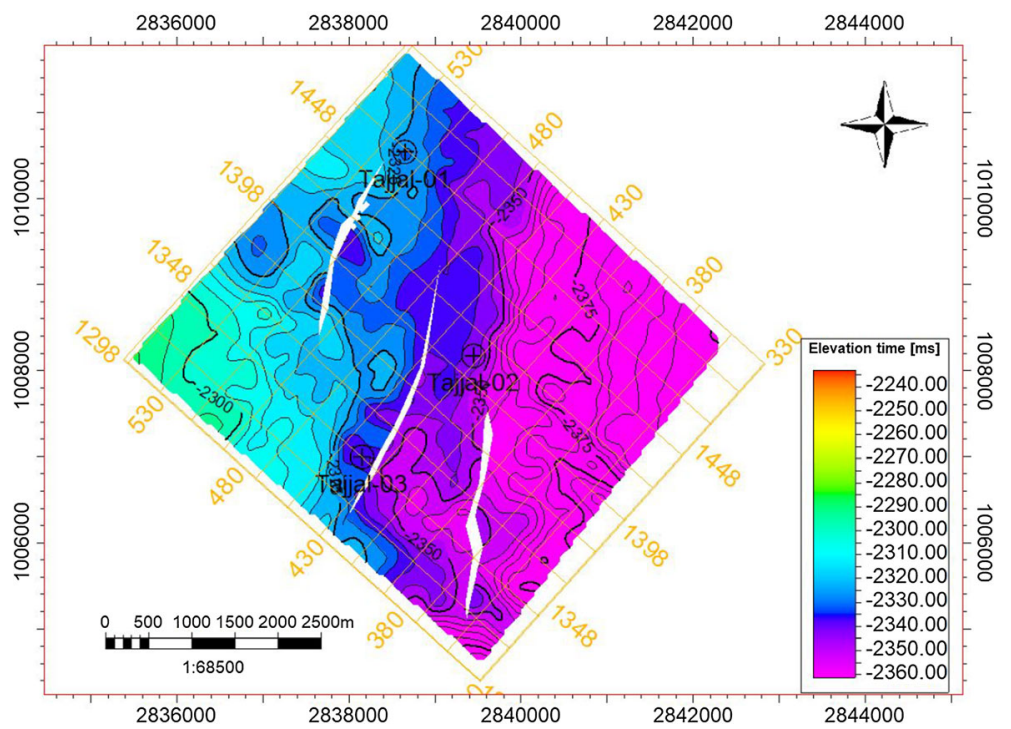

Figure 5. Time-structure map of the C-sand interval of the Lower Goru Formation interpreted from 3D seismic data. The well locations are marked on the map. Fault polygons are drawn along with contours to highlight the main structural trends in the Gambat-Latif block. The colour bar shows time values in seconds.

a broadband inversion technique that uses an initial acoustic impedance model based on well-log data together with seismic-driven velocity information and interpreted seismic horizons. This initial acoustic impedance model is changed, compared to the original seismic data, and sequentially updated until the misfit between the synthetic seismogram (obtained from convolving the wavelet with acoustic impedance), and seismic data is minimised (Veeken 2007; Ashcroft 2011; Simm and Bacon 2014). Several constraints are applied to restrict the inversion solution in a geological sense.
The generalised workflow employed for modelbased seismic inversion is adapted from Simm and Bacon (2014).

\subsection{Inversion methodology}

The model-based post stack seismic inversion applied in this study used seismic and well-log data. A standard seismic data processing sequence, aimed at true amplitude preservation, was applied. The output was time-migrated, zero-phase seismic data with a $35 \mathrm{~Hz}$ dominant frequency. 


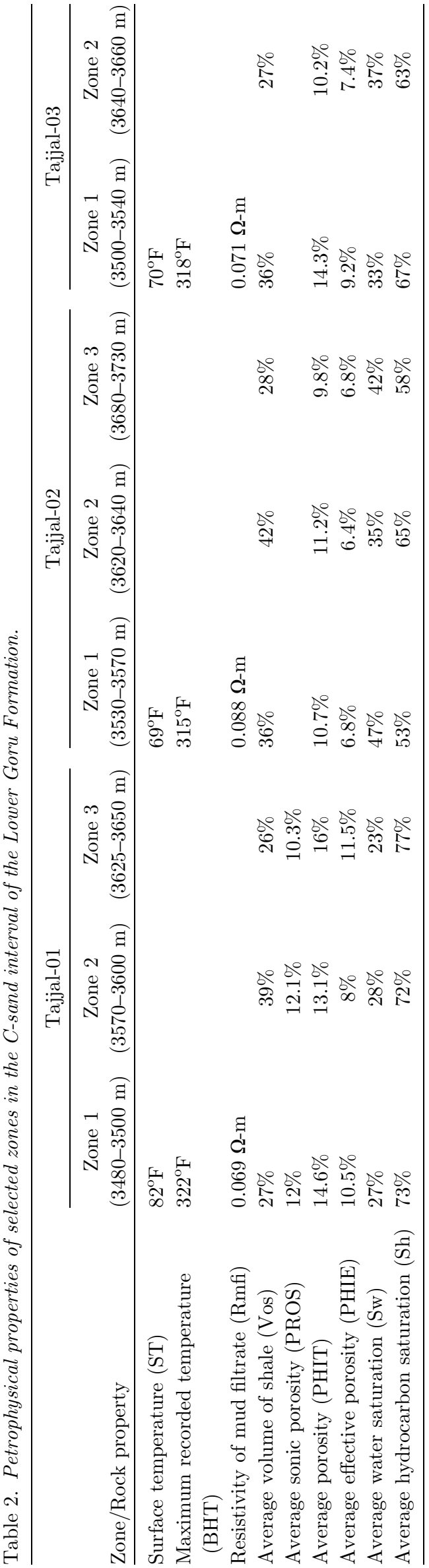

Log-to-seismic calibration was completed by using check-shot and sonic logs.

The essential steps of this method involved the completion of well-to-seismic ties, seismic interpretation, the preparation of an initial acoustic impedance model, and wavelet extraction from seismic data for use in subsequent signal inversion. Well data were used to construct the initial model through the inclusion of a low-frequency trend. Well ties were used for wavelet scaling (e.g., Simm and Bacon 2014) and to complete the necessary adjustments to well ties for a range of stratigraphic intervals. The top and base of horizons were supplied to the inversion process to avoid any tuning effects and to properly map the spatial variability of stratigraphic features; otherwise the sparse welllog coverage in the study area would result in the 'tuning' of relevant stratigraphic features into single seismic reflections.

Since the gathering of accurate wavelet shapes (and scales) is very important for reliable and realistic inversion results (Edgar and van der Baan 2009; Ziolkowski et al. 1998), extracted wavelets were carefully selected and averaged to their phase and amplitude. As the spatial variability and depth of the interval of interest are relatively small, it was reasonable to use an averaged wavelet in this work.

Low-frequency models were built by using well$\log$ data and interpreted horizons from seismic profiles or volumes. Low-frequency merging was performed to better characterize realistic stratigraphic features, their lateral extension and boundaries in the background geological model, a step necessary to achieve realistic impedance inversions (Sams and Saussus 2013; Li and Zhao 2014). It is worth stressing that band-limited seismic data do not contain the original low frequency spectrum of the acquired signal, as it is filtered out ('cut-off') during processing (Ray and Chopra 2015; Azevedo and Soares 2017). Without this lower frequency content, the quantitative prediction of reservoir properties is somewhat inaccurate and non-unique (Pendrel 2015; Sams and Carter 2017).

Low-frequency models can also be prepared by converting seismic velocities into acoustic impedance and density data (Dutta and Khazanehdari 2006). However, the low frequency models constructed using seismic velocities are susceptible to important interpretation biases because of the noisy nature of seismic velocity (Bacon et al. 2007). Also, they require the definition of a calibration 
factor between wells that cross the interpreted seismic volumes or profiles (Sams and Saussus 2013).

Due to the unavailability of pre-stack data, it was impossible to prepare a realistic velocity model in this work. Hence, a broadband impedance model was prepared using well-log data and interpreted horizons on the 3D seismic volume, thus helping to interpolate any relevant information between wells.

Seismic inversion resulted in the generation of acoustic impedance profile, which was further used as an input to estimate the desired reservoir attributes, i.e., porosity. For the model-based inversion method, a starting model constructed by interpolating well data along the interpreted seismic horizons, is changed and iteratively checked against the seismic data. The estimated impedance was convolved with the extracted seismic wavelet. The comparison of modelled and seismic trace yielded the error. The inversion procedure is stopped in case of small calculated errors, otherwise the initial model could be updated until the calculated error was small enough.

\subsection{Geostatistical analyses}

Geostatistical techniques relate different parameters of interest to reservoir characterization. Reservoir parameters derived from different data sets, and of different scales, are compared to reach a meaningful geological interpretation (Kelkar and Perez 2002). The spatial distribution of reservoir parameters is usually computed and quantified by geostatistical techniques (Pyrcz and Deutsch 2014). A linear relationship between welland seismic-driven attributes, namely acoustic impedance and porosity, was established in this work to quantify the spatial distribution of porosity in the entire seismic cube (Doyen 1988; Grana and Dvorkin 2011). Afterwards, estimated porosity was calibrated at the corresponding well locations.

\section{Results}

\subsection{Petrophysics}

In this study, complete suites of wire-line data are used to delineate reservoir zones within the $\mathrm{C}$-sand interval of Lower Goru member (figure 6). Different petrophysical properties for each zone are listed in table 2 . The volume of shale varies within the multiple sandy intervals of the Lower Goru Formation. These zones exhibit variable porosity values due to the presence of shale intercalations. Zone 3 is only delineated in the Tajjal-01 and Tajjal-02 well. Since shale intervals within the sands can be of the laminated, structural, dispersed types, or any combination of these aforementioned types, their distribution greatly affects the porosity of the C-sand interval (Ali et al. 2016).

The cross-plot of effective porosity, volume of shale and acoustic impedance in figure 7 shows important details about the lithology of the C-sand interval in all three interpreted wells. Overall, sand layers are composed of porous (sand), tight (sand) and mixed facies (sand-shale intercalations) (figure 7). High effective porosity and low impedance are representative of hydrocarbon-bearing porous sandstone. Sands record low effective porosity with relatively high acoustic impedance, whereas low effective porosity and an intermediate range in acoustic impedance represent intercalations of sand and shale (figure 7).

We have also applied the Lambda-Mu-Rho (LMR) cross-plot technique to efficiently discriminate between different facies (Goodway et al. 1997; Das and Chatterjee 2018). In particular, Lambda-Rho corresponds to the bulk impedance (incompressibility) and $\mathrm{Mu}-\mathrm{Rho}$ corresponds to the shear impedance (rigidity), and both are highly sensitive to the effect of fluid. In hydrocarbon sands, Lambda-Rho shows low incompressibility values (Goodway et al. 1997; Das and Chatterjee 2018). Figure 8 represents the result from the application of the LMR cross-plot technique on Tajjal-01, Tajjal-02 and Tajjal-03. Gas sand, tight sand, shaly gas sand and shale facies are identified based on the cut-off values of Lambda-Rho and Mu-Rho (Goodway et al. 1997; figure 8).

\subsection{Model-based seismic inversion}

The generalised workflow for our model-based inversion is adapted from Simm and Bacon (2014). Wavelet extraction is a fundamental step in seismic inversion; hence, wavelets at their corresponding well locations were extracted from the $\mathrm{C}$-sand interval of the Lower Goru Formation. The shape and characteristic amplitude (and phase) of wavelets do not change within the area of interest 


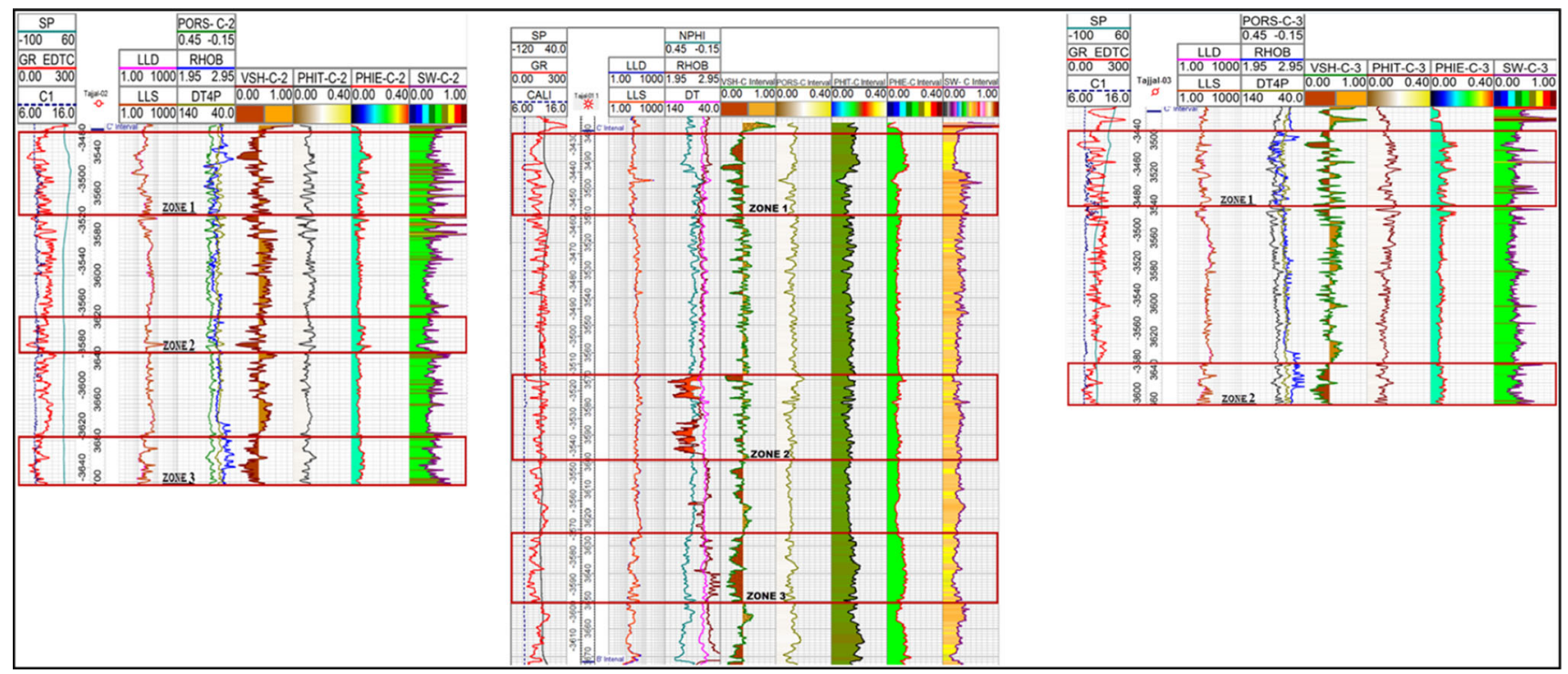

Figure 6. Well-log display and petrophysical analysis of the C-sand interval of the Lower Goru Formation encountered in the Tajjal-01, Tajjal-02 and Tajjal-03 wells. Different reservoir intervals within the Lower Goru Formation are marked by the red rectangles. In each well-log panel, the first track represents lithological data, the second track represents the resistivity data, and the third track represents the porosity data. The remainder of the tracks present derived petrophysical properties such as the volume of shale, porosity, and water saturation. The high values of the deep laterolog (LLD) curve suggest that water saturation is low and hydrocarbon saturation is high despite the moderate values of effective porosity estimated in this work.

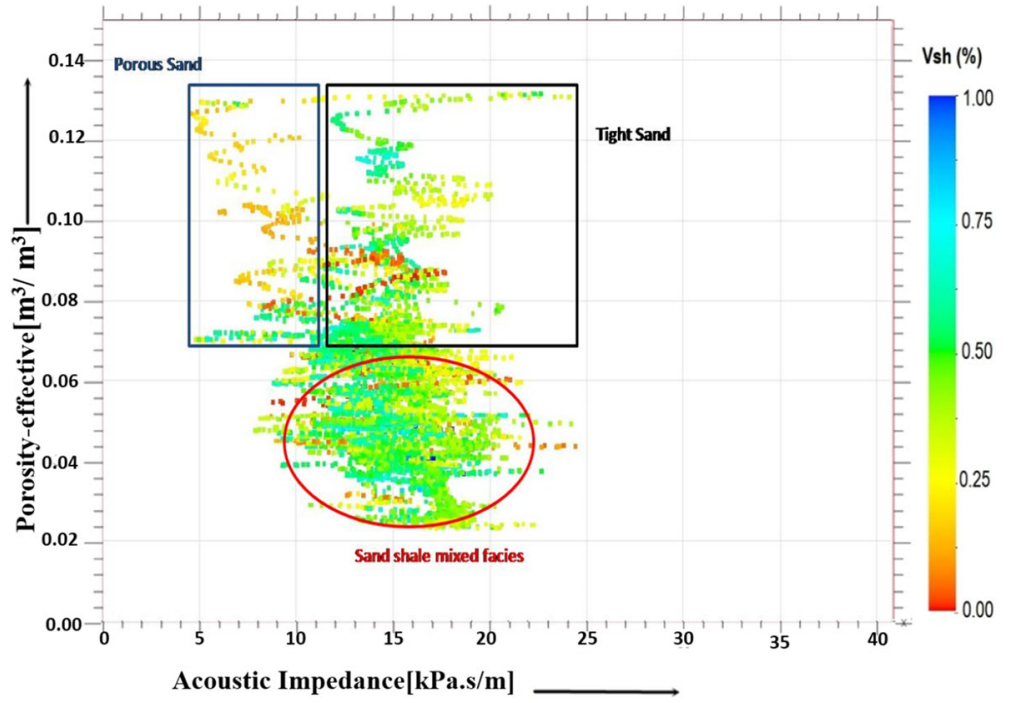

Figure 7. Cross-plot of acoustic impedance vs. effective porosity (in fraction) for the C-sand interval based on all available well-log data. Different types of reservoir sands and sand shale facies are recognized based on the gamma ray information.

(figure 9). Therefore, it was thought reasonable to use an average wavelet (based on our extracted wavelets) in the post-stack seismic inversion.

The average wavelet is shown in the right column of figure 9 together with amplitude and phase spectrum. The shape of the average wavelet resembles that of the extracted wavelet. Figure 10 shows an arbitrary seismic line passing through the three interpreted wells. The synthetic seismograms at the well locations, prepared by convolving the average wavelet with the corresponding acoustic impedance, are superimposed to the seismic profile in figure 10.

Figure 11 shows the low frequency model used for the model-based inversion implemented in this study. This low frequency model assures the inversion is consistent with the background geological information by including sub-seismic 


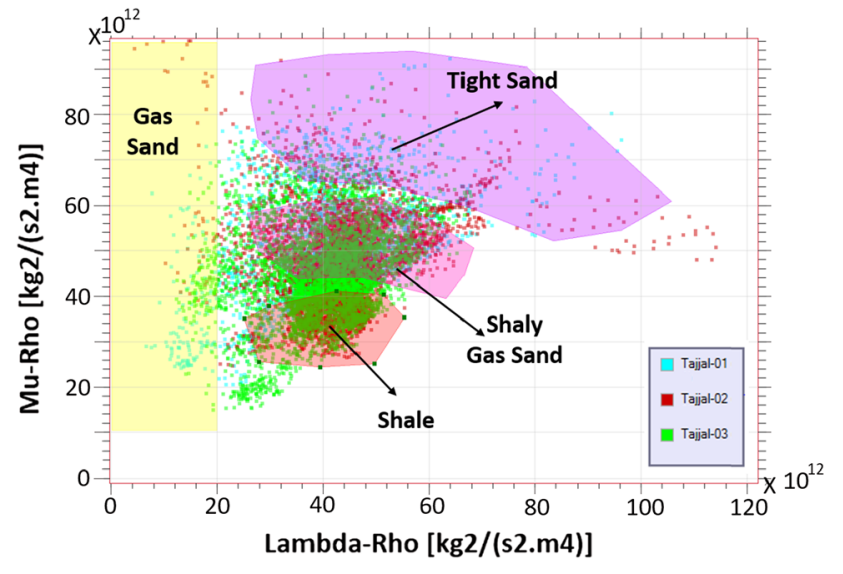

Figure 8. Cross-plot of Lambda-rho vs. Mu-Rho for the C-sand interval utilizing all available well-log data. Different types of facies are recognized based on the cut-off values of Lambda-rho vs. Mu-Rho.

frequencies in the final computation. This stabilizes the inversion workflow by introducing temporal limits and spatial variations to the interpreted seismic horizons (Dutta and Khazanehdari 2006; Pendrel 2015; Azevedo and Soares 2017). Due to the non-uniqueness of seismic inversion, higherthan and lower-than-real seismic frequencies will appear in the inverted data. Therefore, it is necessary to use a band-pass filter before one compares the inverted outputs (Veeken 2007; Li and Zhao 2014).
A comparison of acoustic impedance derived from well- and model-based inversions is shown in figure 12. The acoustic impedance match is good within the C-sand interval; hence, the inverted acoustic impedance can be used to quantify reservoir properties in the study area.

Figure 13 shows the inverted acoustic impedance for a cross-section joining the three exploration wells considered in this work. The upper part of the Lower Goru Formation shows very high impedance. The B- and D-sand intervals show higher acoustic impedance when compared to the C-sand interval (figure 13). The spatial variation of acoustic impedance within the C-sand interval is also characteristically smooth (figure 13).

In a density section extracted along the arbitrary line (figure 14), the light green and light blue colours are representative of density values of $2.5-2.6 \mathrm{~g} / \mathrm{cm}^{3}$, typical of porous sand layers. A sand layer with high density $\left(\sim 2.8 \mathrm{~g} / \mathrm{cm}^{3}\right)$ is observed in the upper part of the Lower Goru Formation. It is observed that density is low in the B- and C-sand intervals at Tajjal-01, while it gradually increases laterally to show relatively higher values in the vicinity of wells Tajjal-02 and Tajjal-03. These two wells consequently show a relative decrease in porosity. Density is low in the vicinity of Tajjal-01 and increases eastwards, likely
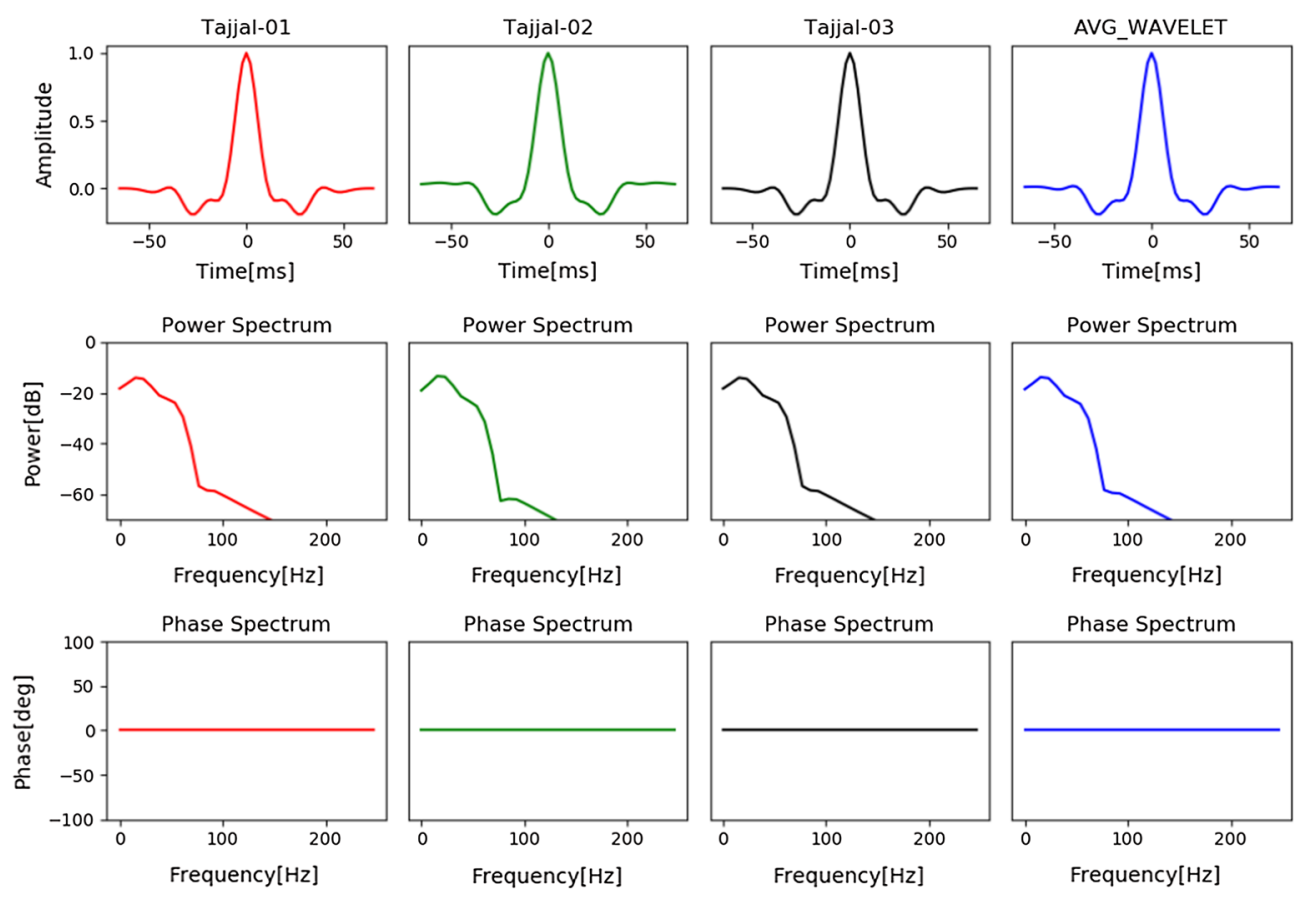

Figure 9. Wavelet extracted from the seismic data at the respective well locations. The column to the right shows the average of corresponding wavelets, power spectrum and phase spectrum. Despite the fact that the main lobes of wavelets appear similar, whereas their side lobes are more variable. All wavelets show similar characteristics in their corresponding power spectrum and phase spectrum plots (2nd and 3rd rows). 


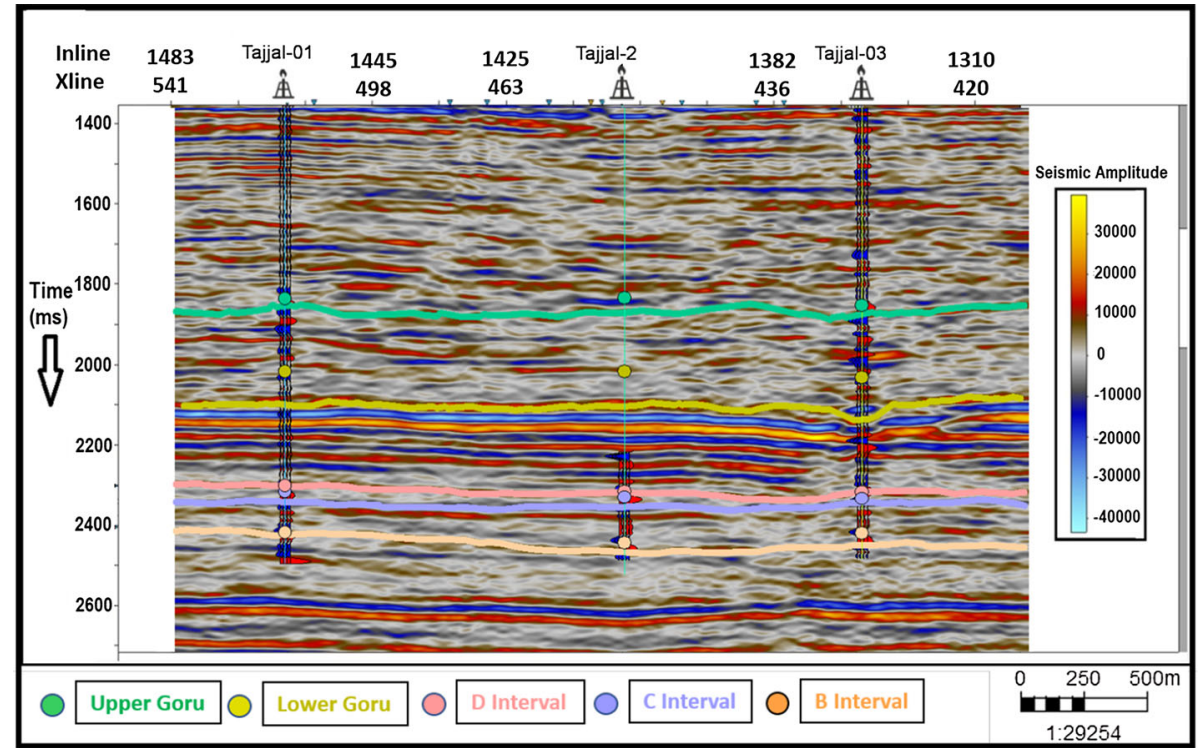

Figure 10. Well-to-seismic ties extracted along the traverse crossing the Tajjal-01, Tajjal-02 and Tajjal-03 wells. Synthetic seismograms were constructed in this figure by using an average wavelet. The average wavelet is good approximation for the seismic wavelet, as shown by the very good match between the synthetic seismic wavelets and the seismic section.

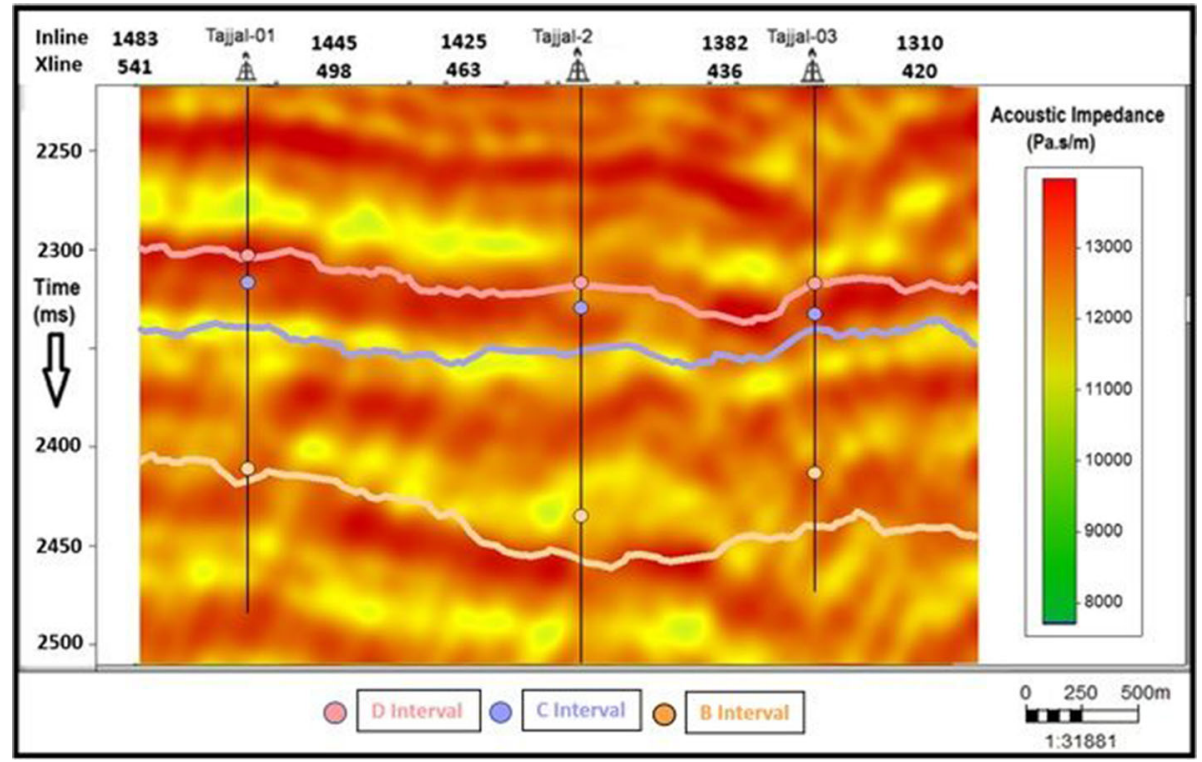

Figure 11. Low frequency model input for model based seismic inversion applied in this work along a seismic line crossing the three interpreted wells.

in association with harder lithologies. High density may represent large matrix volumes, i.e., a smaller percentage of pores; hence, a low effective porosity may exist but filled with saline water or mineral fluids, instead of oil and gas.

\subsection{Porosity estimation}

Figure 15 shows acoustic impedance cross-plot against effective porosity. An upscaling of the well logs is required to plot acoustic impedance against effective porosity and generate a geostatistical function. Upscaling reduces the number of samples in the well logs. The best-fit line, in a least-square sense, shows a good correlation. The inverse linear relationship between acoustic impedance and porosity is well established in the geological context of the Indus Basin. This linear relationship is also valid on a seismic scale. The linear relationship between normalized acoustic impedance and $\varphi_{e}$ 


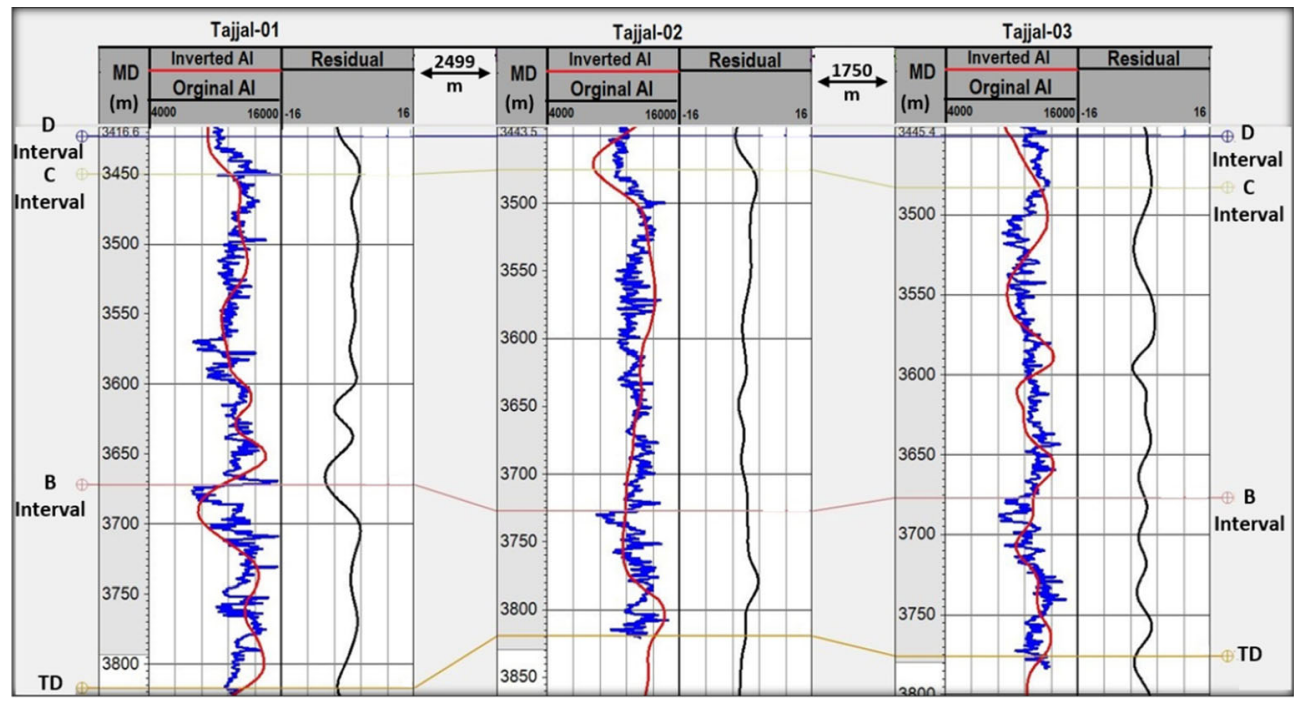

Figure 12. Comparison between post-stack inversion (red) and filtered acoustic impedance (blue) derived from wells Tajjal-01, Tajjal-02 and Tajjal-03. Black curves on the right-hand side of each panel show the difference in acoustic impedance amongst well-log and model-based inversions.

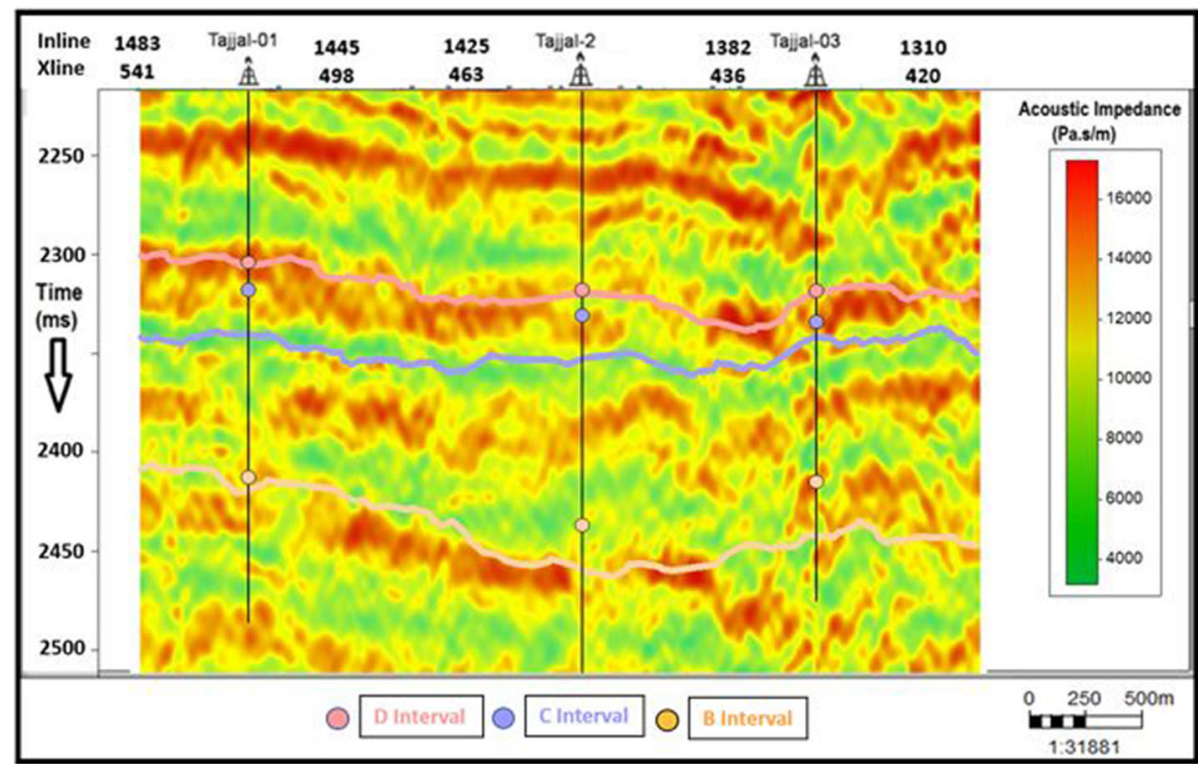

Figure 13. Model-based inverted acoustic impedance profile extracted through wells Tajjal-01, Tajjal-02 and Tajjal-03. The position of key stratigraphic markers is shown.

with a correlation coefficient $(R)$ value of 0.75 or $75 \%$ is, for the study area:

$$
\varphi_{e}=-0.39 \times A I+0.40 .
$$

Here, $A I$ is the inverted impedance from the model-based inversion. The root mean square (RMS) error of fitting is 0.0162 and computed by using the relationship from Barnston (1992).

Acoustic impedance is further used to estimate the effective porosity for the different sandy intervals along an arbitrary line. The inverted cross-section for effective porosity in figure 16 shows variations in effective porosity from top to bottom, with relatively high values within the C-sand interval, i.e., $\sim 10 \%$ at Tajjal-01, decreasing in the Tajjal-02 and Tajjal-03 wells. Different ranges of porosities are also clear for the C-sand interval. These lower porosities are indicative of tight sandy intervals with shale intercalations, whereas in other zones porosity is relatively high within the $\mathrm{C}$-sands. 


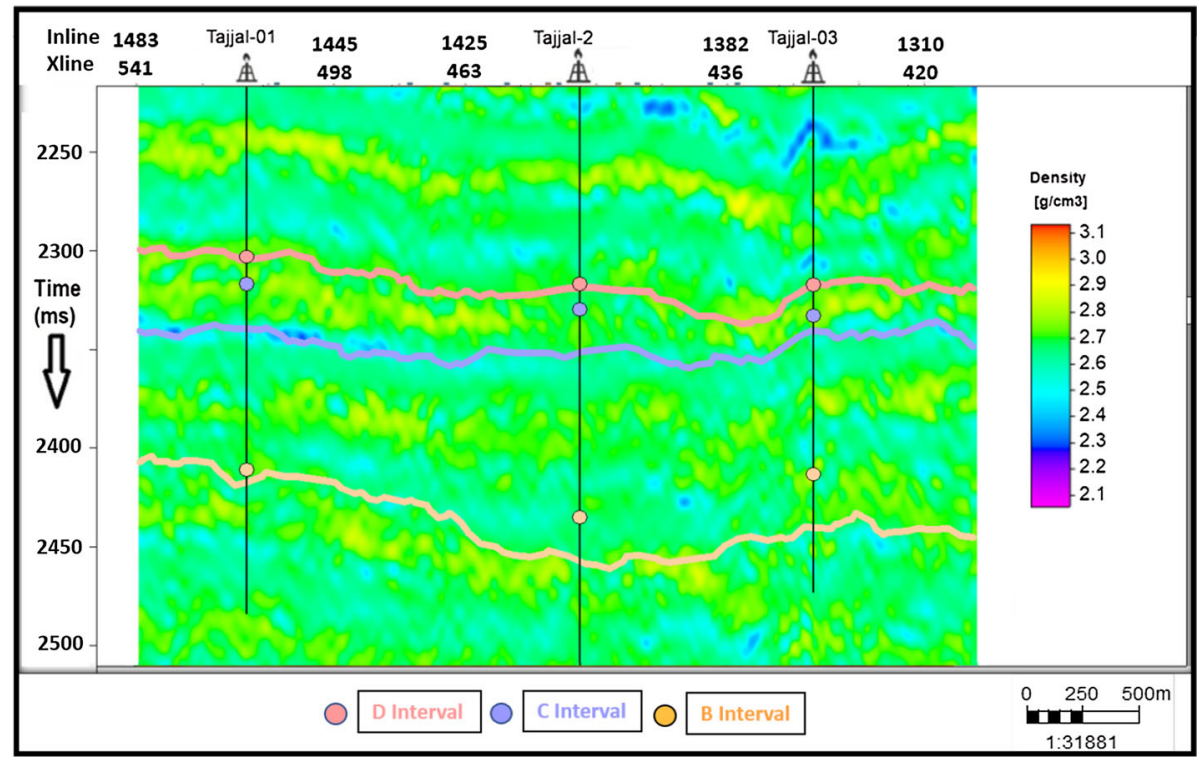

Figure 14. Density section extracted through wells Tajjal-01, Tajjal-02 and Tajjal-03.

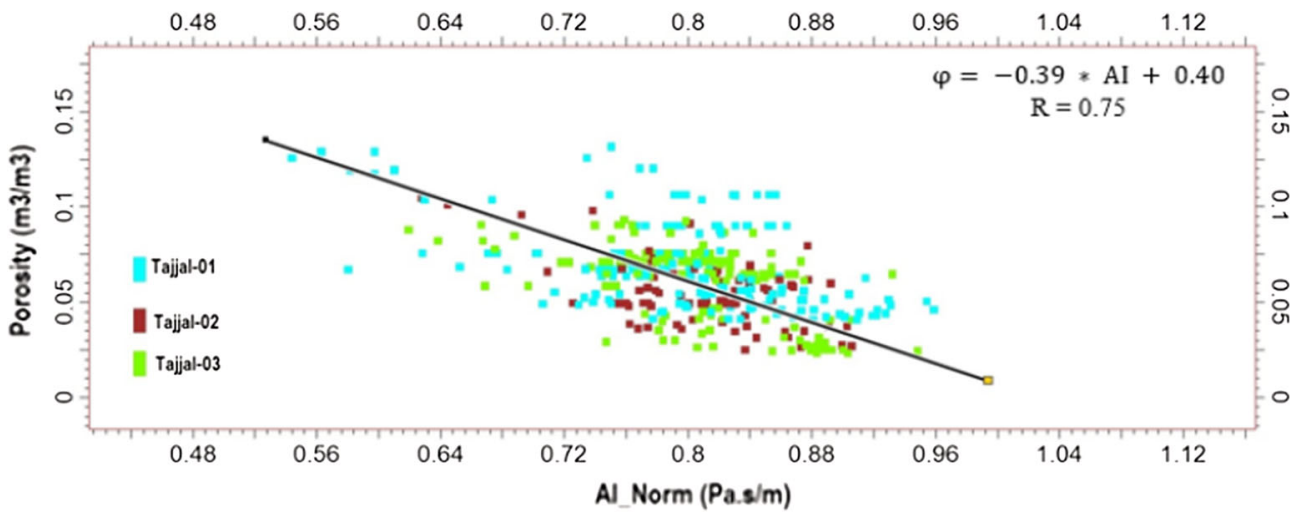

Figure 15. A cross-plot of normalized acoustic impedance and effective porosity (in fraction) based on all available well-log data (Tajjal-01, Tajjal-02 and Tajjal-03) to develop a linear geostatistical relationship. The normalized acoustic impedance is calculated by dividing each sample of acoustic impedance by the maximum of the absolute value. Such a normalized value is used to limit dynamic range of acoustic impedance from -1 to 1 .

\section{Discussion}

Although well data provide high vertical resolution and the best estimates for reservoir porosity, the sparse coverage of wells makes it hard to reasonably estimate porosity in between wells. Seismic inversion helps to estimate the spatial distribution of effective porosity in reservoir intervals constrained by well data (Pyrcz and Deutsch 2014). The integration of petrophysics, geo-statistics, seismic surface data and seismic inversion addresses the problem of porosity estimation (Dolberg et al. 2000; Avseth et al. 2005; Grana and Dvorkin 2011; Adekanle and Enikanselu 2013; Das and Chatterjee 2016).
Since well and seismic data map different aspects of reservoir properties at different scale, their direct calibration might lead to unsatisfactory results. Uncertainties may occur if the lithofacies within depositional facies are not well recognized and incorporated in subsequent stages of data integration. In this study, post-stack seismic inversion shows good result because absolute acoustic impedance can capture the variations in sand-shale distribution. The accuracy of the result is judged around the well locations; away from the well location the uncertainty will creep into the results depending on the pattern and distribution of lithofacies. Sorting, grain distribution, reservoir connectivity and compartmentalization may 


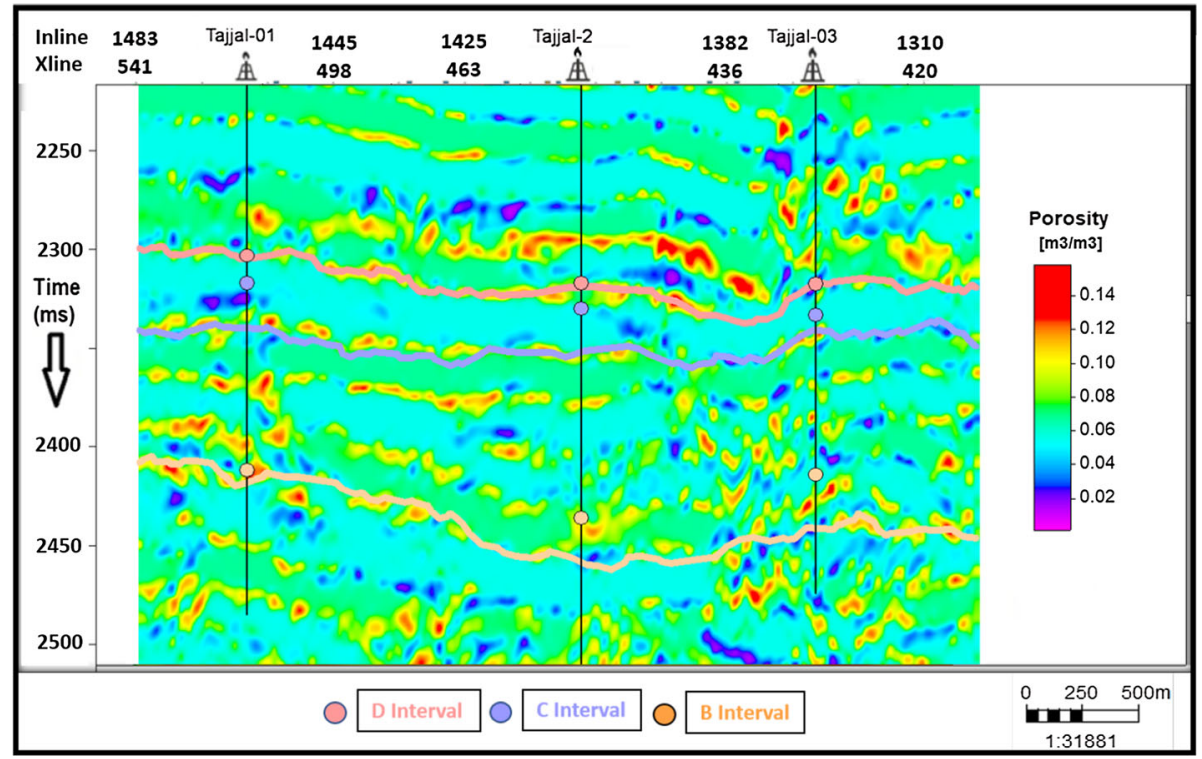

Figure 16. Porosity section based on model-based acoustic impedance inversion along a profile crossing wells Tajjal-01, Tajjal-02 and Tajjal-3. Porosity values are represented in terms of fraction.

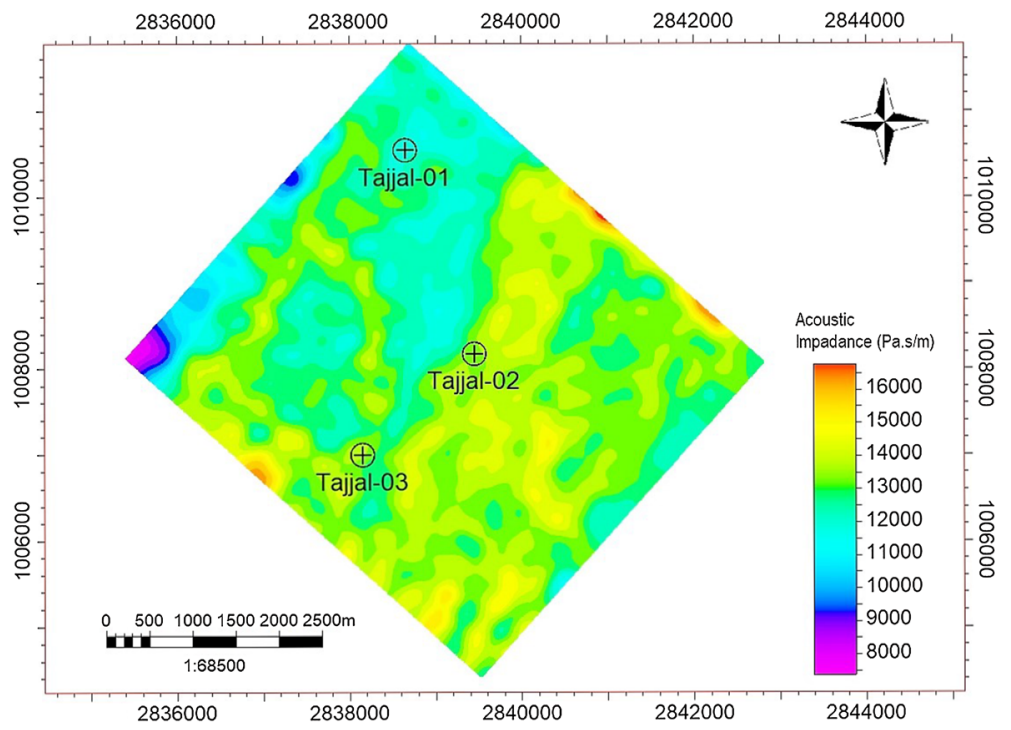

Figure 17. Acoustic impedance (AI) map of C-sand derived from the seismic inversion results for the Gambat-Latif block.

further result in additional uncertainty. Since in our case sands are regularly distributed, though their thickness varies, our post-stack results are reliable.

Figure 17 is the main result of the model-based inversion completed in this study. This figure is constrained by well-log data, and shows a good fit between borehole-derived and inversion-derived acoustic impedance at consecutive wells. The lateral continuity of the C-Sand interval is well captured by the inversion methodology. Furthermore, porosity distribution estimated from inversion within the reservoir interval is realistic when compared to the geology of the area. The latter detail also helps to quantify reservoir compartmentalization, sand distribution and porosity variations.

By using an established geostatistical relationship (figure 15) the estimated acoustic impedance of the C-sand interval (figure 17) was converted into porosity values (figure 18). Porosity in the C-sand varies from $1 \%$ (cyan colour) to $16 \%$ (yellow colour) which is in agreement with the porosity values estimated from well-log data. The porosity distribution varies considerably at the three well locations considered in this study, but there is an excellent match between the petrophysical- and inversion-based porosities in the Tajjal-01 and 


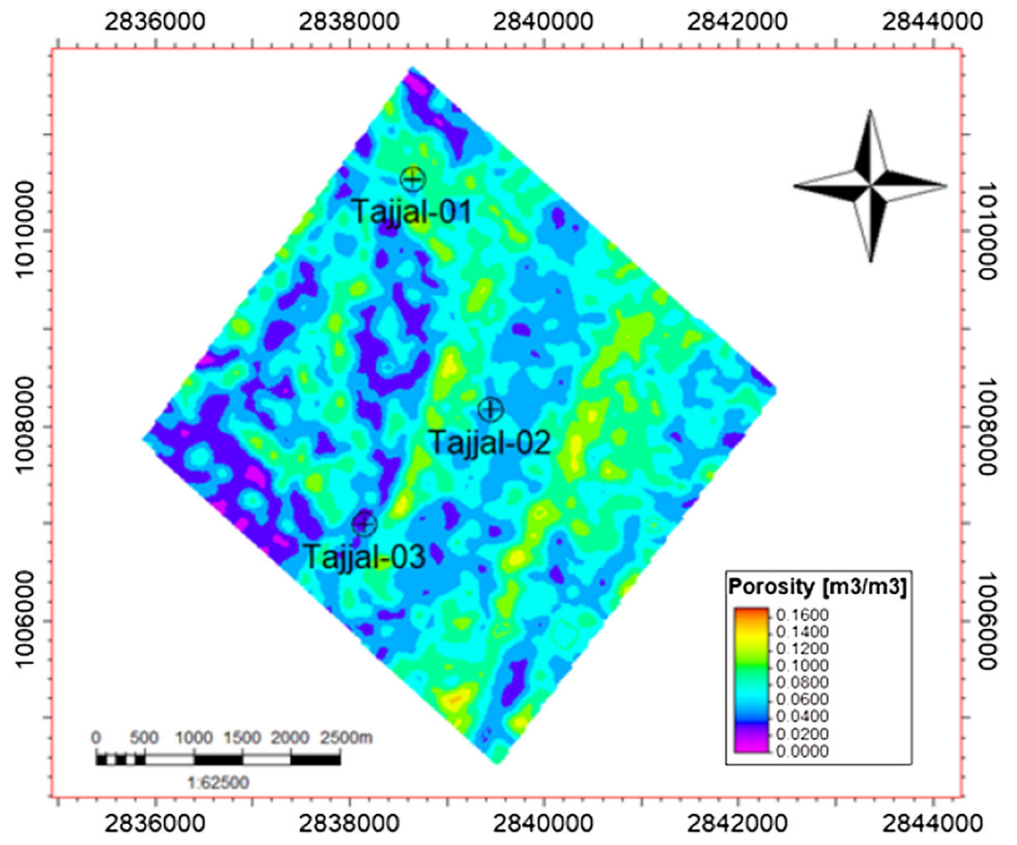

Figure 18. Porosity distribution within the C-sand derived from the seismic inversion results for the Gambat-Latif block. The porosity is represented in terms of fraction.

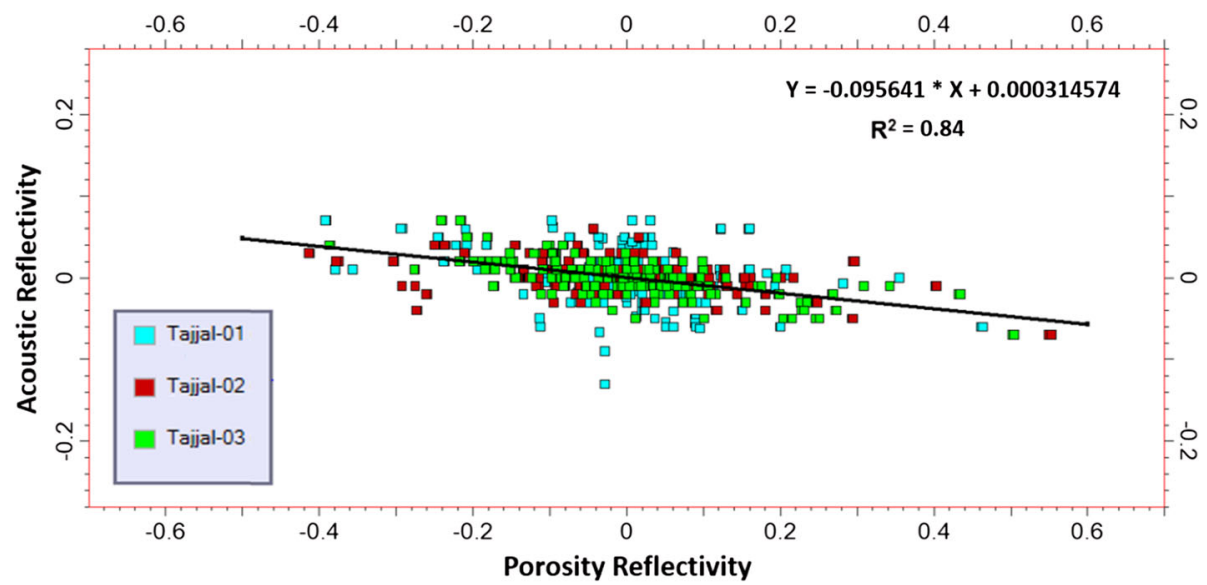

Figure 19. Cross-plot between acoustic impedance and porosity reflectivity with a linear regression fit based on all available well-log data. The correlation coefficient for this cross-plot is $84 \%$ and value of $\boldsymbol{n}$ (slope) is -0.095641 .

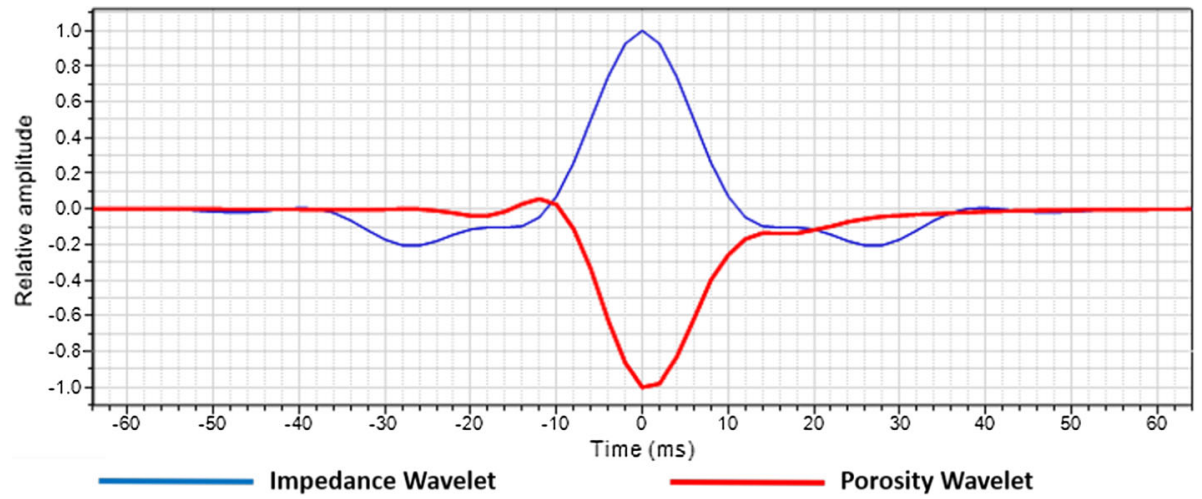

Figure 20. Acoustic impedance and porosity wavelet. The porosity wavelet is obtained by multiplying the value of $\boldsymbol{n}$ to the acoustic impedance wavelet, and shows opposite trend to acoustic impedance wavelet. 


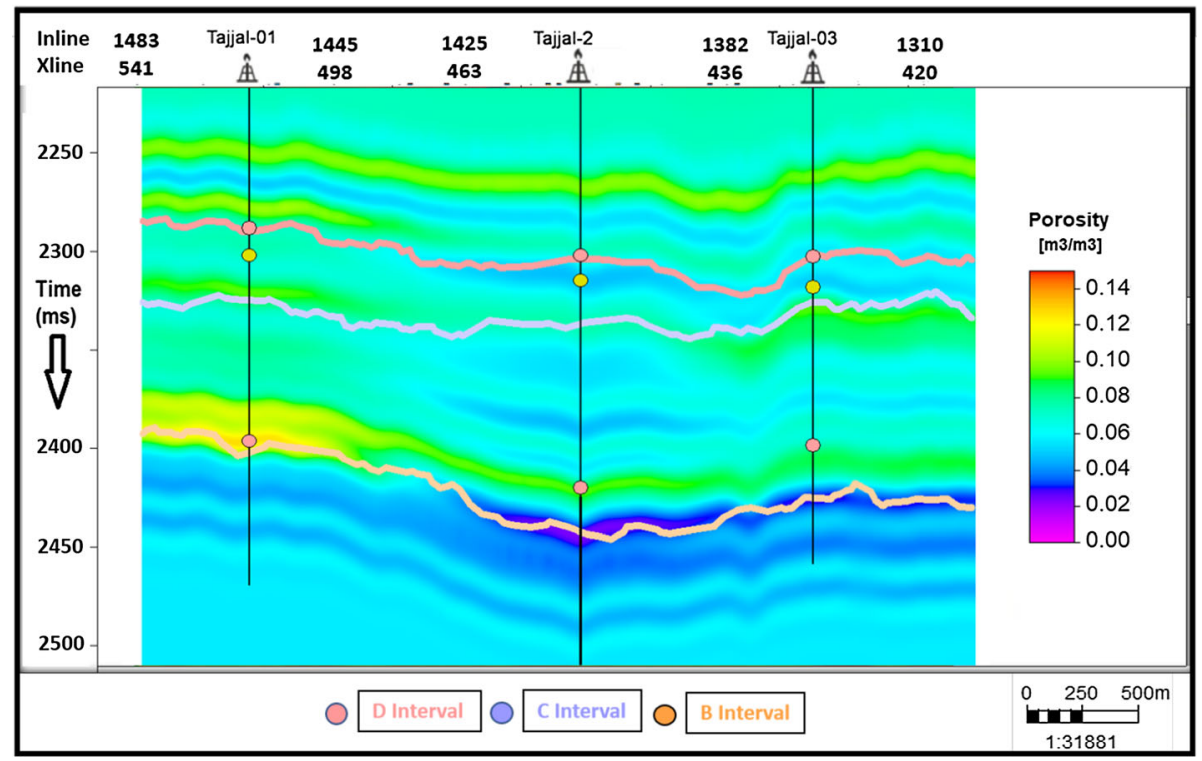

Figure 21. Porosity profile based on the direct seismic inversion porosity estimation technique of Kumar et al. (2016) extracted in a cross-section along wells Tajjal-01, Tajjal-02 and Tajjal-3. The porosity is represented in terms of fraction.

Tajjal-02 wells. Within the C-sand interval, the porosity varies from $4 \%$ to $16 \%$, with narrow patches of lower porosity (tight sand) occurring in its interior.

We also used a direct inversion to estimate porosity in post stack seismic data, a technique proposed by (Rasmussen and Maver 1996). The mathematical details and procedure to accomplish the results is outlined in Kumar et al. (2016) and Rasmussen and Maver (1996). This technique linearly maps the porosity, and requires the computation of acoustic impedance reflectivity $\left(r_{z}\right)$ and porosity reflectivity $\left(r_{\varphi}\right)$ obtained via equations (5 and 6) of Kumar et al. (2016). In particular, $r_{\varphi}$ is calculated by utilizing the porosity derived from the porosity logs as given by

$$
r_{\varphi}=\frac{1}{2}\left(\log \left(\frac{\varphi_{i+1}}{1-\varphi_{i+1}}\right)-\log \left(\frac{\varphi_{i}}{1-\varphi_{i}}\right)\right),
$$

where the numerators and denominators of each logarithmic terms represent the porosities and matrix of the respective sample points within the well. The relation between $r_{z}$ and $r_{\varphi}$ is given as (Kumar et al. 2016):

$$
r_{z}=n r_{\varphi}
$$

Here, $n$ is the correlation factor (slope) obtained via fitting a linear regression relation in a cross-plot between $r_{\varphi}$ and $r_{z}$. Figure 19 shows the cross-plot between the $r_{\varphi}$ and $r_{z}$ with a correlation coefficient of $84 \%$ and a slope of -0.095641 . The value of $n$ is then

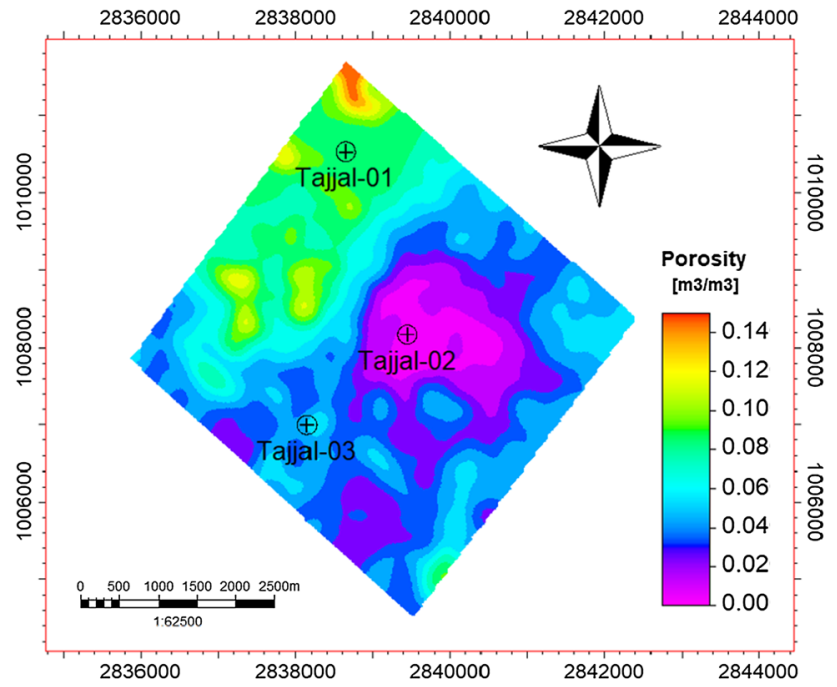

Figure 22. Porosity distribution in the C-sand derived from the direct seismic inversion porosity estimation technique of Kumar et al. (2016) for the Gambat-Latif block. The porosity is represented in terms of fraction.

multiplied with the extracted acoustic impedance wavelet to obtain the porosity wavelet, as shown in figure 20. This porosity wavelet is further utilized for the direct porosity estimation using the model-based inversion technique described in this paper (figures 21 and 22). A comparison in terms of actual and predicted porosities obtained by both inversion techniques, together with their RMS errors, is also presented in figures 23 and 24 for each well.

It is important to mention that porosity and its spatial distribution is governed by geological factors. Depositional setting, sediment flux (type and 


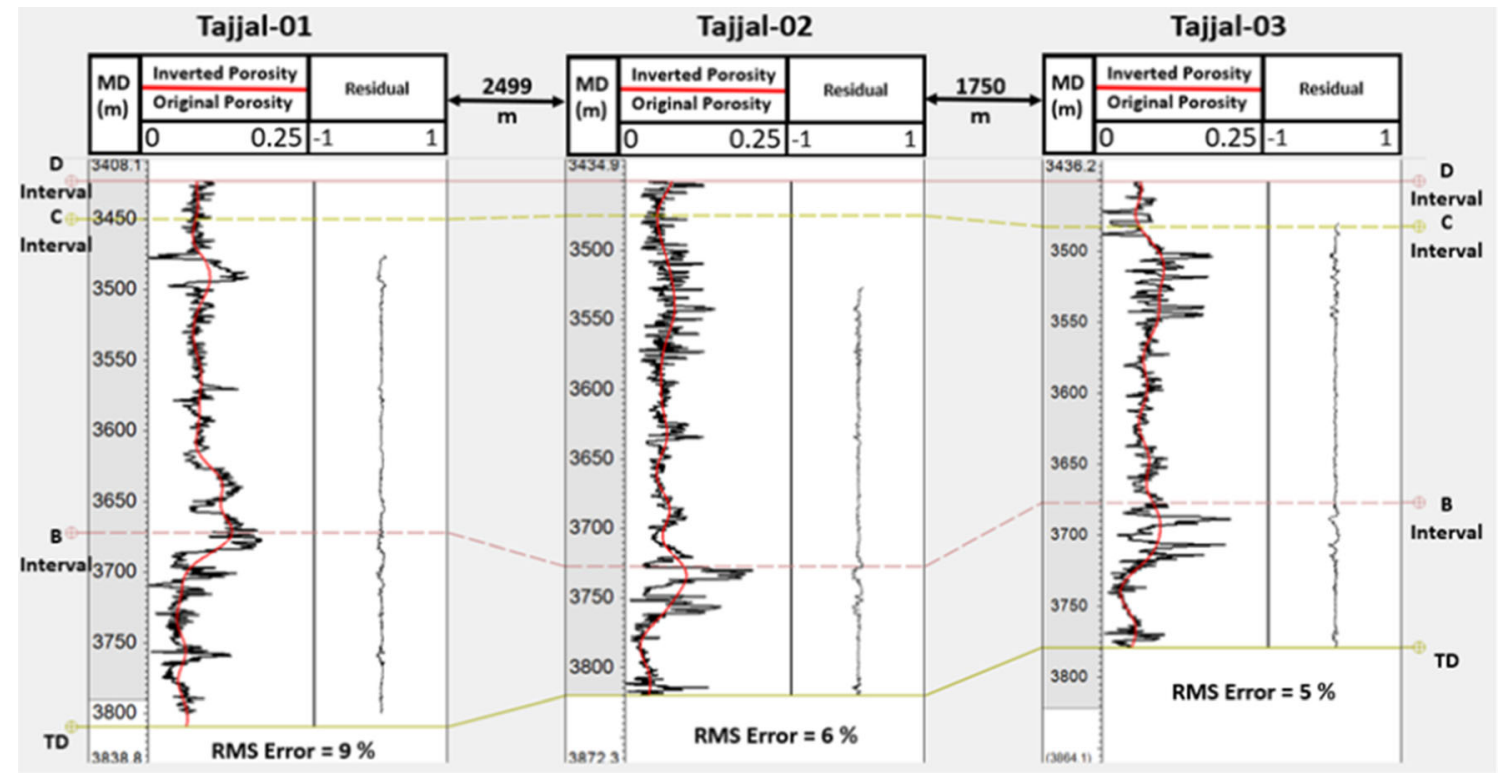

Figure 23. Comparison between actual porosity (black) derived from wells Tajjal-01, Tajjal-02 and Tajjal-03, and predicted (inverted) porosity (red) using the acoustic impedance wavelet and model-based inversion techniques. Black curves on the righthand side of each panel show the porosity difference from well-log and model-based inversion results. The RMS error is also presented for each well.

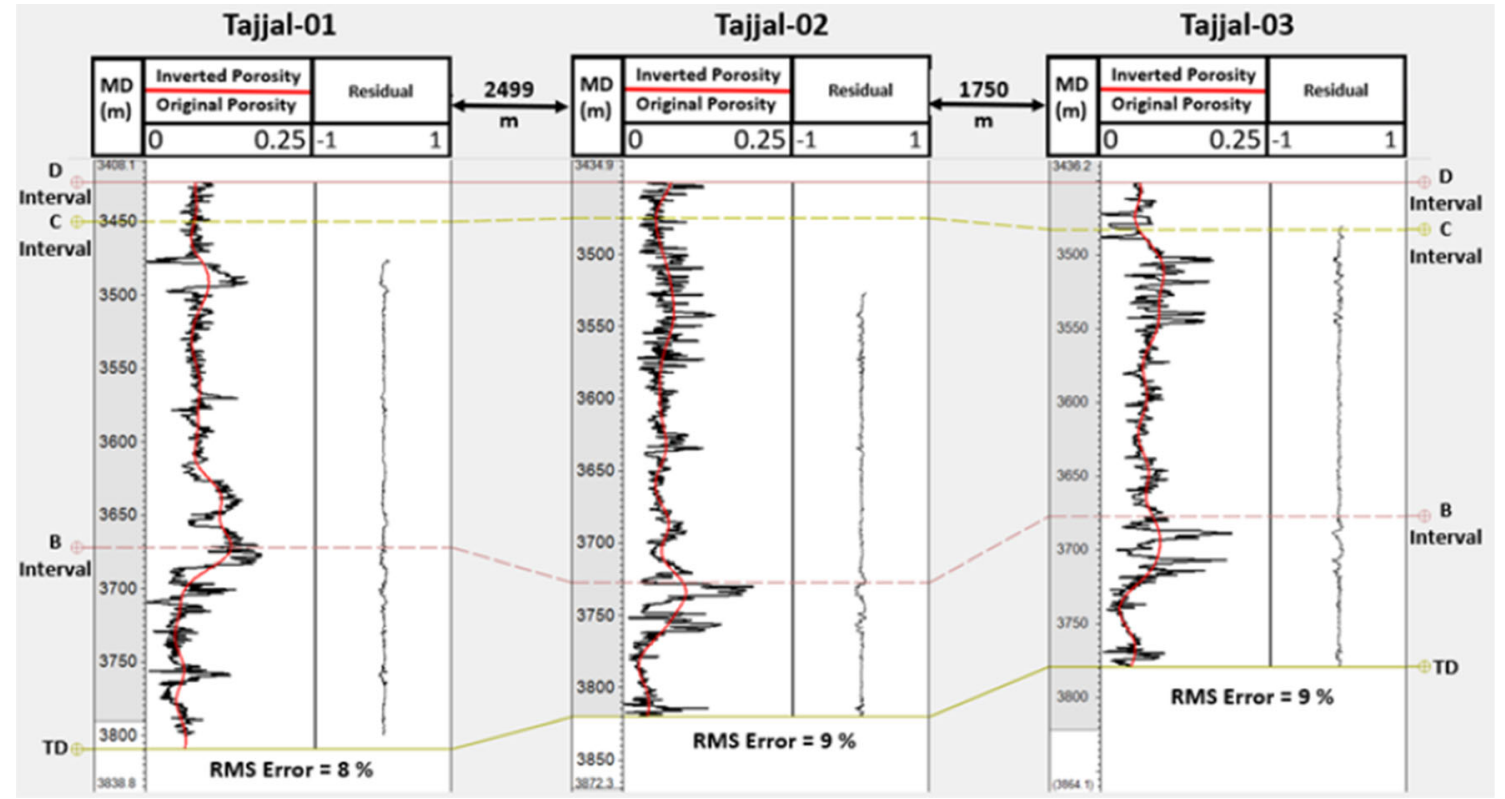

Figure 24. Comparison between actual porosity (black) derived from wells Tajjal-01, Tajjal-02 and Tajjal-03 and predicted (inverted) porosity (red) using the direct seismic inversion porosity estimation technique of Kumar et al. (2016). Black curves on the right-hand side of each panel show the porosity difference between well-log and model-based inversion results. The RMS error is also presented for each well.

amount of sediment) and post depositional processes are the main factors controlling porosity. In the study area, there is a pronounced and appreciable range in porosity values due to aforementioned factors. The porosity in the wells, few kilometres apart from each other, is highly variable. Overall, both the inversion techniques applied in this study show the reasonably small
RMS errors between the actual and predicted porosity, which further improves our confidence on the inverted results (figures 23 and 24). Moreover, it can be observed that both our inversion techniques map the low porosity (tight sands) encountered in the Tajjal-02 and Tajjal-03 wells (suspended and abandoned) and the relatively high porosity at Tajjal-01 (gas-producing well). 
It is imperative to mention that, to recognize and address the uncertainties related with spatial porosity mapping, multiple point simulation and stochastic inversion techniques may be applied. However, these are not within the scope of this study; they require lithofacies modelling, conceptual geological modelling, and additional data. This might result in better estimation and uncertainty quantification but at the cost of additional human and computational resources. Thus, the spatial porosity mapping in this study may be used as an input for further sophisticated modelling.

\section{Conclusions}

Spatial porosity estimation and mapping is a challenging task, especially in the case where limited data of different scales is available. In this work, spatial porosity is estimated and mapped in the Gambat-Latif block in the Central Indus Basin, Pakistan by using model based post-stack seismic inversion. The estimated porosity values range from 1 to $16 \%$ in the studied reservoir zone. Variations in the spatial distribution of porosity within the C-sand interval of the Lower Goru Formation are due to the presence of shale, and to the style(s) of shale distribution within sand intervals. These uncertainties associated with spatial porosity mapping are difficult to capture and quantify due to resolving power of seismic, datasets of different scales and the geostatistical relationships that are valid in the vicinity of wells. The initial low frequency model, constructed from seismic and well data interpretation, is a crucial parameter for the inversion workflow. It may be concluded that porosity mapping by post-stack seismic inversion was deemed reliable in this study, and may be so in similar scenarios. It is hoped that this case study will encourage further studies to use other techniques, i.e., multipoint Geostatistical simulations and stochastic inversions to find a more realistic geological consistent models for porosity distributions. However, the latter methods demand more data, their scaling, and further human and computational resources.

\section{Acknowledgements}

The authors would like to thank Directorate General of Petroleum Concessions (DGPC), Pakistan, for allowing the use of seismic and well-log data for research and publication purposes and Department of Earth Sciences, Quaid-i-Azam
University, Islamabad, Pakistan, Cardiff University, UK for providing the basic requirements to complete this work. We are thankful to the reviewers/Associate Editor of this manuscript for critically reviewing and improving the manuscript.

\section{Author statement}

Dr Muhammad Toqeer perceived the idea and partially executed this idea of the research. Dr Aamir Ali took the idea and proposed the methodology and implemented it with the help of his student Mr Ashar Khan. Mr Ashar Khan has contribution in terms of collection of the literature and raw data. Dr Tiago M Alves have given the support in terms of modern research methods and helped in the interpretation of the data. Mr Zubair has given the software and data support and computed the maps. Dr Matloob Hussain has contributed in interpretation and finalization of the manuscript.

\section{References}

Abbasi S, Kalwar Z and Solangi S 2016 Study of structural styles and hydrocarbon potential of Rajan Pur Area, Middle Indus Basin, Pakistan; BUJ ES 1 36-41.

Afzal J, Williams M and Aldridge R 2009 Revised stratigraphy of the lower Cenozoic succession of the Greater Indus Basin in Pakistan; J. Micropalaeontol. 28 7-23.

Ahmed N, Fink P, Sturrock S, Mahmoo T and Ibrahim M 2004 Sequence stratigraphy as predictive tool in Lower Goru Fairway, Lower And Middle Indus Platform, Pakistan, Pakistan Association of Petroleum Geoscientists, Annual Technical Conference, Islamabad, pp. 17-18.

Akhter G, Ahmed Z, Ishaq A and Ali A 2015 Integrated interpretation with Gassmann fluid substitution for optimum field development of Sanghar area, Pakistan: A case study; Arab. J. Geosci. 8 7467-7479.

Adekanle A and Enikanselu P A 2013 Porosity prediction from seismic inversion properties over 'XLD'Field, Niger Delta; Am. J. Sci. Indus. Res. 4(1) 31-35.

Alavi M 2004 Regional stratigraphy of the Zagros fold-thrust belt of Iran and its proforeland evolution; Am. J. Sci. 304 1-20, https://doi.org/10.2475/ajs.304.1.1.

Ali A, Alves T M, Saad F A, Ullah M, Toqeer M and Hussain M 2018 Resource potential of gas reservoirs in South Pakistan and adjacent Indian subcontinent revealed by post-stack inversion techniques; J. Nat. Gas Sci. Eng. 49 41-55.

Ali A, Hussain M, Rehman K and Toqeer M 2016 Effect of shale distribution on hydrocarbon sands integrated with anisotropic rock physics for AVA modelling: A case study; Acta Geophys. 64 1139-1163.

Angeleri G P and Carpi R 1982 Porosity prediction from seismic data; Geophys. Prospect 30 580-607, https://doi. org/10.1111/j.1365-2478.1982.tb01328.x. 
Anwer H M, Ali Alves T M and Zubair A 2017 Effects of sandshale anisotropy on amplitude variation with angle (AVA) modelling: The Sawan gas field (Pakistan) as a key case study for South Asia's sedimentary basins; J. Asian Earth Sci. 147 516-531, https://doi.org/10.1016/j.jseaes.2017.07. 047.

Ashcroft W 2011 A Petroleum Geologist's Guide to Seismic Reflection, Wiley-Blackwell.

Avseth P, Mukerji T and Mavko G 2005 Quantitative seismic interpretation: Applying rock physics tools to reduce interpretation risk, Cambridge University Press, https://doi. org/10.1017/CBO9780511600074.

Azeem T, Chun W, Khalid P and Qing L 2017 An integrated petrophysical and rock physics analysis to improve reservoir characterization of Cretaceous sand intervals in Middle Indus Basin, Pakistan; J. Geophys. Eng. 14 212-225.

Azevedo L, Amaro C, Grana D, Soares A and Guerreiro L 2017 Coupling geostatistics and rock physics in reservoir modelling and characterization; Soc. Petrol. Eng., https://doi. org/10.2118/188470-MS.

Azevedo L and Soares A 2017 Geostatistical methods for reservoir geophysics: Advances in oil and gas exploration 8 production, Springer, Cham, https://doi.org/10.1007/9783-319-53201-1.

Aziz O, Hussain T, Ullah M, Bhatti A S and Ali A 2018 Seismic based characterization of total organic content from the marine Sembar shale, Lower Indus Basin, Pakistan; Mar. Geophys. Res; 39(4) 491-508.

Bacon M, Simm R and Redshaw T 2007 3-D seismic interpretation, Cambridge University Press, https://doi. org/10.1017/CBO9780511802416.

Barnston A G 1992 Correspondence among the correlation, RMSE, and Heidke forecast verification measures: Refinement of the Heidke score; Wea. Forecast. 7(4) 699-709.

Berger A, Gier S and Krois P 2009 Porosity-preserving chlorite cements in shallow-marine volcaniclastic sandstones: Evidence from Cretaceous sandstones of the Sawan gas field, Pakistan; AAPG Bull. 93 595-615.

Bosch M, Carvajal C, Rodrigues J, Torres A, Aldana M and Sierra J 2009 Petrophysical seismic inversion conditioned to well-log data: Methods and application to a gas reservoir; Geophysics $\mathbf{7 4}$ O1-O15, https://doi.org/10.1190/1. 3043796.

Bosch M, Mukerji T and Gonzalez E F 2010 Seismic inversion for reservoir properties combining statistical rock physics and geostatistics: A review; Geophysics $\mathbf{7 5}$ 75A165, https://doi.org/10.1190/1.3478209.

Caers J, Avseth P and Mukerji T 2001 Geostatistical integration of rock physics, seismic amplitudes, and geologic models in North Sea turbidite systems; Lead Edge 20 308, https://doi.org/10.1190/1.1438936.

Chen Q and Sidney S 1997 Seismic attribute technology for reservoir forecasting and monitoring; Lead Edge $\mathbf{1 6}$ 445-448, https://doi.org/10.1190/1.1437657.

Chopra S and Marfurt K J 2007 Seismic attributes for prospect identification and reservoir characterization; Geophys. Dev. Ser. 11 465, https://doi.org/10.1190/1.9781560801900.

Das B and Chatterjee R 2016 Porosity mapping from inversion of post-stack seismic data; Georesursy 18(4) 306-313.

Das B and Chatterjee R 2018 Well log data analysis for lithology and fluid identification in Krishna-Godavari Basin, India; Arab. J. Geosci. 11(10) 231.
Das B, Chatterjee R, Singha D K and Kumar R 2017 Poststack seismic inversion and attribute analysis in shallow offshore of Krishna-Godavari basin, India; J. Geol. Soc. India 90 32-40, https://doi.org/10.1007/s12594-017-06614.

de Terra H, de Chardin P T and Paterson T T 1936 Joint geological and prehistoric studies of the late Cenozoic in India; Science $\mathbf{8 3} 233-236$.

Delaplanche J, Lafet Y and Sineriz B 1982 Seismic reflection applied to sedimentology and gas discovery in the Gulf of Cadiz; Geophys. Prospect. 30 1-24.

Dolberg D, Helgesen J, Hanssen T, Magnus I, Saigal G and Pedersen B 2000 Porosity prediction from seismic inversion, Lavrans Field, Halten Terrace, Norway; Lead Edge 19 392-399, https://doi.org/10.1190/1.1438618.

Doyen P 1988 Porosity from seismic data: A geostatistical approach; Geophysics 53 1263-1275, https://doi.org/10. 1190/1.1442404.

Dutta N and Khazanehdari J 2006 Estimation of formation fluid pressure using high-resolution velocity from inversion of seismic data and a rock physics model based on compaction and burial diagenesis of shales; Lead Edge $\mathbf{2 5}$ 1528-1539, https://doi.org/10.1190/1.2405339.

Edgar J and van der Baan M 2009 How reliable is statistical wavelet estimation. In: SEG Technical Program Expanded Abstracts 2009, Society of Exploration Geophysicists, pp. 3233-3237, https://doi.org/10.1190/1.3255530.

Gogoi T and Chatterjee R 2019 Estimation of petrophysical parameters using seismic inversion and neural network modelling in Upper Assam basin, India; Geosci. Frontiers 10(3) 1113-1124, https://doi.org/10.1016/j.gsf.2018.07. 002 .

Goodway B, Chen T and Downtown J 1997 Improved AVO fluid detection and lithology discrimination using Lame petrophysical parameters, 67th Annual international Meeting, SEG Expanded Abstracts, pp. 183-186.

Grana D and Dvorkin J 2011 The link between seismic inversion, rock physics, and geostatistical simulations in seismic reservoir characterization studies; Lead Edge $\mathbf{3 0}$ 54-61, https://doi.org/10.1190/1.3535433.

Hearts J R, Nelson P H and Paillet F L 2002 Well Logging for Physical Properties: A Handbook for Geophysicists, Geologists and Engineers, 2nd edn, John Wiley \& Sons, Chichester.

Iravani M, Rastegarnia M, Javani D, Sanati A and Hajiabadi S H 2017 Application of seismic attribute technique to estimate the 3D model of hydraulic flow units: A case study of a gas field in Iran; Egypt. J. Pet., https://doi.org/ 10.1016/j.ejpe.2017.02.003.

Jafari M, Nikrouz R and Kadkhodaie A 2017 Estimation of acoustic-impedance model by using model-based seismic inversion on the Ghar Member of Asmari Formation in an oil field in southwestern Iran; Lead Edge 36 487-492.

Kadri I 1995 Petroleum geology of Pakistan, Pakistan Petroleum Limited, Karachi.

Karbalaali H, Shadizadeh S and Riahi M 2013 Delineating hydrocarbon bearing zones using elastic impedance inversion: A Persian Gulf example; Iran. J. Oil. Gas. Sci. Tech. 2 8-19.

Kazmi A and Abbasi I 2008 Stratigraphy $\&$ Historical Geology of Pakistan, Department \& National Centre of Excellence in Geology, Peshwar, Pakistan. 
Kazmi A H and Rana R A 1982 Tectonic map of Pakistan 1:2000000: Map showing structural features and tectonic stages in Pakistan, Geological survey of Pakistan.

Kelkar M and Perez G 2002 Applied Geostatistics for Reservoir Characterization, Society of Petroleum Engineers.

Khattak F, Shafeeq M and Mansoor A 1999 Regional trends in porosity and permeability of reservoir horizons of Lower Goru Formation, Lower Indus Basin, Pakistan; J. Hydrocarb. Res. 11 37-50.

King D E 1990 Incorporating geological data in well log interpretation; In: Geological Applications of Wireline Logs, pp. 45-55, https://doi.org/10.1144/gsl.sp.1990.048. 01.06 .

Kumar R, Das B, Chatterjee R and Sain K 2016 A methodology of porosity estimation from inversion of post-stack seismic data; J. Nat. Gas Sci. 28 356-364.

Landa J L, Horne R N, Kamal M M and Jenkins C D 2000 reservoir characterization constrained to well-test data: A field example; SPE Reserv. Eval. Eng. 3 325-334, https:// doi.org/10.2118/65429-PA.

Leite E P and Vidal A C 2011 3D porosity prediction from seismic inversion and neural networks; Comput. Geosci. 37 1174-1180, https://doi.org/10.1016/j.cageo.2010.08.001.

Li M and Zhao Y 2014 Chapter 6 - Seismic inversion techniques. In: Geophysical Exploration Technology Applications in Lithological and Stratigraphic Reservoirs, Elsevier, Oxford, pp. 133-198, https://doi.org/10.1016/B978-012-410436-5.00006-X.

Lindseth R O 1979 Synthetic sonic logs - a process for stratigraphic interpretation; Geophysics 44 3, https://doi. org/10.1190/1.1440922.

Liner C 2016 Elements of 3D seismology, investigations in geophysics; Society of Exploration Geophysicists, https:// doi.org/10.1190/1.9781560803386.

Mukerji T, Avseth P, Mavko G, Takahashi I and González E F 2001 Statistical rock physics: Combining rock physics, information theory, and geostatistics to reduce uncertainty in seismic reservoir characterization; Lead Edge 20313 , https://doi.org/10.1190/1.1438938.

Oldenburg D, Levy S and Stinson K 1986 Inversion of bandlimited reflection seismograms: Theory and practice; Proc. IEEE $\mathbf{7 4}$ 487-497.

Oldenburg D, Scheuer T and Levy S 1983 Recovery of the acoustic impedance from reflection seismograms; Geophysics 48 1318-1337.

Pendrel J 2015 Low frequency models for seismic inversions: Strategies for success. In: SEG Technical Program Expanded Abstracts 2015, Society Exploration Geophysicists, pp. 2703-2707, https://doi.org/10.1190/segam20155843272.1.

Pyrcz M and Deutsch C V 2014 Geostatistical Reservoir Modelling, 2nd edn, Oxford University Press.

Quadri S V 1986 Hydrocarbon prospects of southern Indus basin, Pakistan; Am. Assoc. Pet. Geol. Bull. 70 730-747.

Rasmussen K B and Maver K G 1996 Direct inversion for porosity of post stack seismic data. NPF/SPE European 3-D Reservoir Modelling Conference, pp. 235-246, https:// doi.org/10.2523/35509-ms.

Ray A and Chopra S 2015 More robust methods of lowfrequency model building for seismic impedance inversion. In: SEG Technical Program Expanded Abstracts 2015,
Society of Exploration Geophysicists, pp. 3398-3402, https://doi.org/10.1190/segam2015-5851713.1.

Robison C R, Smith M A and Royle R A 1999 Organic facies in Cretaceous and Jurassic hydrocarbon source rocks, Southern Indus basin, Pakistan; Int. J. Coal Geol. 39 205-225, https://doi.org/10.1016/S0166-5162(98)00046-9.

Rosa A L R 2018 The seismic signal and its meaning; In: The seismic signal and its meaning, Society of Exploration Geophysicists, https://doi.org/10.1190/1.9781560803348.

Russell B and Dommico S 1988 Introduction to seismic inversion methods, $S E G$.

Sams M and Carter D 2017 Stuck between a rock and a reflection: A tutorial on low-frequency models for seismic inversion; Interpretation 5 B17-B27.

Sams M and Saussus D 2013 Practical implications of low frequency model selection on quantitative interpretation results; SEG Tech. Progr. Expand. Abstr., pp. 3118-3122.

Silva M Da, Rauch-Davies M and Cuervo A 2004 Data conditioning for a combined inversion and AVO reservoir characterisation study, 66th EAGE Conf.

Simm R and Bacon M 2014 Seismic Amplitude: An interpreter's handbook, Cambridge University Press.

Singha D K, Shukla P K, Chatterjee R and Sain K 2019 Multichannel 2D seismic constraints on pore pressure- and vertical stress-related gas hydrate in the deep offshore of the Mahanadi Basin, India; J. Asian Earth Sci., https:// doi.org/10.1016/j.jseaes.2019.103882.

Sinha B and Mohanty P 2015 Post stack inversion for reservoir characterization of KG Basin associated with gas hydrate prospects; J. Ind. Geophys. Union 19 200-204.

Teixeira L and Maul A 2020 Quantitative and stratigraphic seismic interpretation of the evaporite sequence in the santos basin, Elsevier, https://www.sciencedirect.com/ science/article/abs/pii/S0264817220304736.

Tiab D and Donaldson E 2015 Petrophysics: Theory and Practice of Measuring Reservoir Rock and Cuid Transport Properties, Gulf Professional Publishing.

Toqeer M and Ali A 2017 Rock physics modelling in reservoirs within the context of time lapse seismic using well log data; Geosci. J. 21 111-122.

Veeken P C H 2007 Seismic Stratigraphy, Basin Analysis and Reservoir Characterisation, Elsevier, Amsterdam.

Veeken P C H and Rauch-Davies M 2006 AVO attribute analysis and seismic reservoir characterization; First Break 24 41-52, https://doi.org/10.3997/1365-2397.2006004.

Veeken P C H and Da Silva M 2004 Seismic inversion methods and some of their constraints; First Break 22 47-70.

Verma S, Bhattacharya S, Lujan B, Agrawal D and Mallick S 2018 Delineation of early Jurassic aged sand dunes and paleo-wind direction in southwestern Wyoming using seismic attributes, inversion, and petrophysical modelling; $J$. Nat. Gas Sci. Eng. 60 1-10, https://doi.org/10.1016/j. jngse.2018.09.022.

Walls J, Dvorkin J and Carr M 2004 Well logs and rock physics in seismic reservoir characterization; Offshore Technol. Conf., https://doi.org/10.4043/16921-MS.

Wandrey C, Law B and Shah H 2004 Sembar Goru/Ghazij composite total petroleum system, Indus and Sulaiman-Kirthar geologic provinces, Pakistan and India; In: Petroleum Systems and Related Geologic Studies in Region 8, South Asia (ed.) Wandrey C J, United States Geological Survey Bulletin, 2208-C. 
Wang Y 2017 Seismic Inversion: Theory and Applications, Wiley Blackwell.

White R 2003 Tying well-log synthetic seismograms to seismic data: The key factors; In: SEG Technical Program Expanded Abstracts 2003, Society Exploration Geophysicists, pp. 2449-2452, https://doi.org/10.1190/1.1817885.

Williams M D 1959 Stratigraphy of the Lower Indus Basin, West Pakistan; In: 5th, New York. Proc, World Petroleum Congress, pp. 377-394.

Yao F and Gan L 2000 Application and restriction of seismic inversion; Pet. Explor. Dev. 27 53-56.

Yilmaz Ö 2001 Seismic data analysis: Processing, inversion, and interpretation of seismic data, investigations in geophysics; Society of Exploration Geophysicists, https:// doi.org/10.1190/1.9781560801580.

Zaigham N and Mallick K 2000 Prospect of hydrocarbon associated with fossil-rift structures of the southern Indus basin, Pakistan; AAPG Bull. $\mathbf{8 4}$ 18331848.

Zhang R, Sen M K, Phan S and Srinivasan S 2012 Stochastic and deterministic seismic inversion methods for thin-bed resolution; J. Geophys. Eng. 9(5) 611-618, https://doi.org/ 10.1088/1742-2132/9/5/611.

Ziolkowski A M, Underhill J R and Johnston R G K 1998 Wavelets, well-ties, and the search for stratigraphic traps; Geophysics 63 297-313.

Corresponding editor: Arkoprovo Biswas 